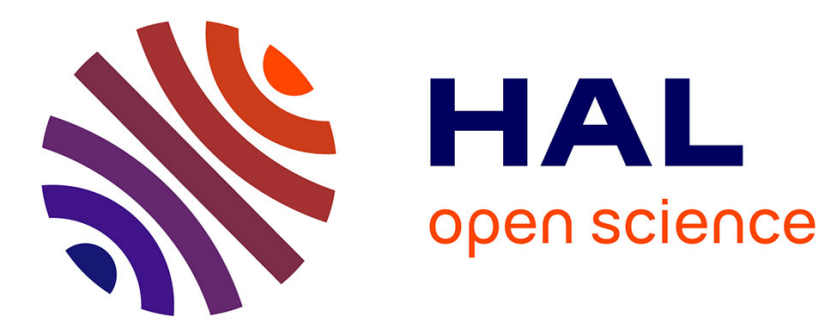

\title{
Implication of a Silyl Cobalt Dihydride Complex as a Useful Catalyst for the Hydrosilylation of Imines
}

\author{
Cassandre C Bories, Marion Barbazanges, Etienne Derat, Marc Petit
}

\section{To cite this version:}

Cassandre C Bories, Marion Barbazanges, Etienne Derat, Marc Petit. Implication of a Silyl Cobalt Dihydride Complex as a Useful Catalyst for the Hydrosilylation of Imines. ACS Catalysis, 2021, pp.14262-14273. 10.1021/acscatal.1c03886 . hal-03425497

\section{HAL Id: hal-03425497 \\ https://hal.science/hal-03425497}

Submitted on 10 Nov 2021

HAL is a multi-disciplinary open access archive for the deposit and dissemination of scientific research documents, whether they are published or not. The documents may come from teaching and research institutions in France or abroad, or from public or private research centers.
L'archive ouverte pluridisciplinaire HAL, est destinée au dépôt et à la diffusion de documents scientifiques de niveau recherche, publiés ou non, émanant des établissements d'enseignement et de recherche français ou étrangers, des laboratoires publics ou privés. 


\section{Implication of a Silyl Cobalt Dihydride Complex as}

\section{a Useful Catalyst for the Hydrosilylation of Imines}

Cassandre C. Bories, Marion Barbazanges, Etienne Derat and Marc Petit*

Sorbonne Université, CNRS, Institut Parisien de Chimie Moléculaire, UMR 8232, 4 place

Jussieu, 75005 Paris, France.

Cobalt, imine reduction, hydrosilylation, DFT, homogeneous catalysis

ABSTRACT. Herein we describe the formation and use of silyl cobalt(III) dihydride complexes as powerful catalysts for the hydrosilylation of a variety of imines starting from a low-valent welldefined cobalt(I) complex. The reaction is efficient at low catalyst loadings with a diverse range

of imines bearing various protecting groups, as well as aliphatic ketimines and quinoline. Kinetics, DFT calculations, NMR spectroscopic studies, deuteration experiments and X-ray diffraction analysis allowed us to propose a catalytic cycle based on silyl dihydrocobalt(III) complexes performing a hydrocobaltation.

\section{INTRODUCTION}

Amines are key motifs in the living world given their essential role in amino acids in biology. ${ }^{1}$ This function is omnipresent in agrochemicals, pharmaceuticals, and in bioactive or natural 
molecules. ${ }^{2}$ In this context, it is necessary to develop robust strategies to introduce amine groups onto molecules of interest. One of the most common strategies is the reduction of $\mathrm{N}$-containing groups such as imine, nitrile, azide or nitro functions. ${ }^{3}$ Among these methods, the reduction of imines is advantageous as they are readily accessible from the corresponding ketones or aldehydes, providing facile access to structurally diverse and tunable substituted amines. Imines can be reduced by hydrogenation, hydrogen transfer or by reaction with hydrides. ${ }^{4}$ However, the direct hydrogenation of imines usually requires high hydrogen pressures. Given the innate and significant risks associated with the handling of pressurized hydrogen, these methods are often unfeasible, practically and economically, in an academic laboratory setting. While reactions with aluminum and boron hydrides such $\mathrm{LiAlH}_{4}$ and $\mathrm{NaXBH}_{3}(\mathrm{X}=\mathrm{H}, \mathrm{CN} \ldots)$ are operationally simple as they do not require additional metals, they face several drawbacks such as sensitivity to air, lack of functional group tolerance. Additionally, the stoichiometric requirement of hydrides leads to the generation of huge amounts of aluminum and boron waste. Recently, hydrogen transfer reactions have emerged as promising strategies to synthetize amine groups. Within this category of reactions, hydrosilylation is an appealing choice given the abundance of silicon on earth and the commercial availability of a variety of silanes which are fairly air stable and a lot easier to handle than hydrogen gas or metallic hydrides. Noble metals such as Ir, Ru, Rh, and Pd have been widely investigated for imine hydrosilylation. ${ }^{5}$ However, catalysis is currently facing the critical challenge of replacing these noble metals due to their low abundance, increasing cost and toxicity. ${ }^{6}$ Over the past few decades, impressive hydro-elementations strategies have been developed using main group catalysts (s-block and p-block) including strong Lewis acids, frustrated Lewis pairs (FLPs), commercially available bases and even catalyst-free conditions have been reported. ${ }^{7}$ In the field of

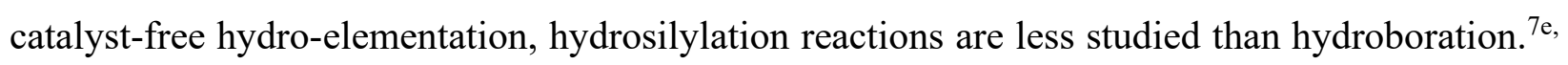


${ }^{7 \mathrm{~g}}$ Moreover, regarding the reduction of imines, aryl-imines are most commonly investigated with rare examples of alkyl ketimines. ${ }^{7 \mathrm{c}, 8}$ Obviously, earth-abundant metals such as $\mathrm{Fe}, \mathrm{Ni}, \mathrm{Cu}, \mathrm{Zn}$ and Co have also emerged as good alternative catalysts (Scheme 1a). Using these metals, very good results were obtained for the reduction of aldimines, and harsher conditions were generally necessary for the reduction of ketimines. In the specific case of $\mathrm{Zn}-$ and $\mathrm{Cu}$-based catalysts, only ketimines bearing electron-withdrawing groups were reduced. ${ }^{9}$ Regarding $\mathrm{Fe}^{10}$ and $\mathrm{Ni},{ }^{11}$ sophisticated ligands such as carbenes were required together with long reaction times and scarce examples of aliphatic ketimine reduction can be found in the literature. Cobalt is often described as the most mature non noble metal for cross-coupling reactions, $\mathrm{C}-\mathrm{H}$ bond functionalization and more recently for the hydrogenation of unsaturated compounds. ${ }^{12}$ However, its application towards the reduction of imines is still in its infancy. ${ }^{13}$ In fact, the direct hydrogenation of imines with cobalt under a $\mathrm{H}_{2}$ atmosphere is limited to only four references in the literature (Scheme $1 \mathrm{~b}$ ). In 1986 Okamato, a pioneer in this field, described the first example of imine hydrogenation using a bis(dioximato)cobalt quinine complex under mainly stoichiometric conditions. ${ }^{14}$ In 2012, Amézquita-Valencia and Cabrera described the use of $\mathrm{Co}_{2}(\mathrm{CO})_{8} /(R)$-BINAP as the catalytic mixture for the asymmetric reduction of biphenyl ketimines. ${ }^{15}$ The same year Hanson described the use of a cobalt complex bearing a bis[2-(dicyclohexylphosphino)ethyl]amine ligand for the hydrogenation of various unsaturated bonds, including three aldimines but no ketimines were reduced. ${ }^{16}$ Finally, in 2014 Von Wangelin reported the use of an arene-cobalt complex for hydrogenations, but again, the scope of aldimines is narrow and no ketimine reduction was reported. ${ }^{17}$ Although some examples of hydrogenation are described, the use of silanes for the reduction of imines with cobalt complexes has not been reported in the literature. ${ }^{18}$ 


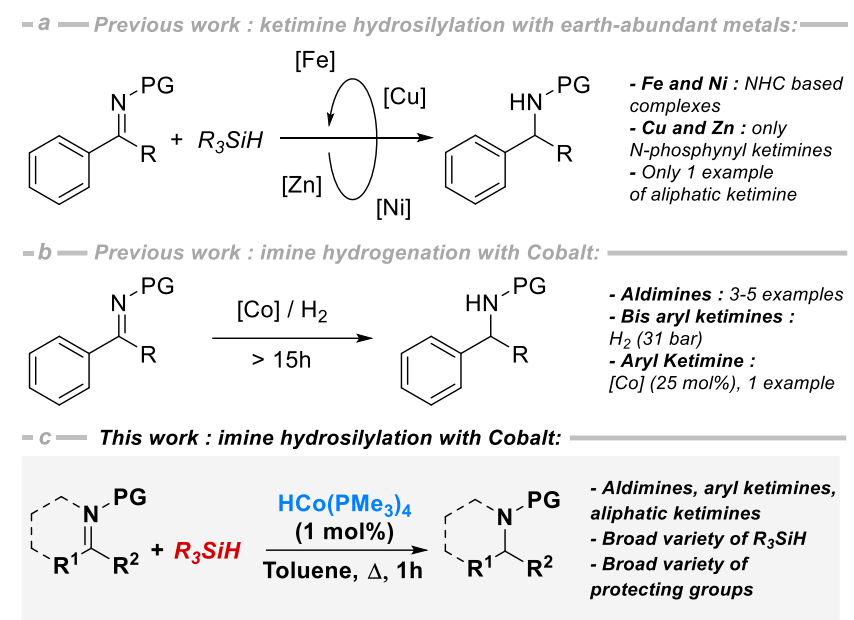

Scheme 1. Imine reduction with earth-abundant metals

During the last decade, our group ${ }^{19}$ and others ${ }^{20}$ have been interested in the activity of two welldefined low valent cobalt complexes $\mathrm{Co}\left(\mathrm{PMe}_{3}\right)_{4}$ and $\mathrm{HCo}\left(\mathrm{PMe}_{3}\right)_{4}$ for bond activation. Using these two complexes, we have shown that simple catalysts can be competitive with noble metals for several applications. Moreover, using this "single-component catalyst" strategy, ${ }^{21}$ we were able to gain mechanistic insight into the hydroarylation and hydrosilylation of alkynes. From these previous studies, we determined that imines can easily enter cobalt's coordination sphere and that various silanes can smoothly undergo oxidative addition onto these cobalt( 0 or I) species. ${ }^{19}$

\section{RESULTS AND DISCUSSION}

With these observations in mind, we anticipated that these two low-valent cobalt complexes would be efficient catalysts for the hydrosilylation of imines (Scheme 1c). Table 1 summarizes our initial screening of reaction conditions. 
Table 1. Reaction condition optimization. ${ }^{\mathrm{a}}$

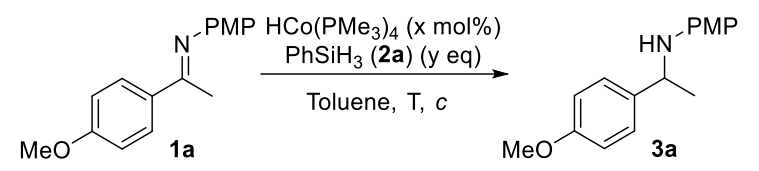

\begin{tabular}{ccccccc}
\hline entry $^{\mathrm{a}}$ & $\mathrm{y}(\mathrm{eq})$ & $\mathrm{x}(\mathrm{mol} \%)$ & $\mathrm{T}\left({ }^{\circ} \mathrm{C}\right)$ & Time & $c$ & Conversion $^{\mathrm{b}}$ \\
\hline 1 & 2 & 10 & 20 & $24 \mathrm{~h}$ & $0.25 \mathrm{M}$ & $6 \%$ \\
2 & 2 & 10 & 50 & $24 \mathrm{~h}$ & $0.25 \mathrm{M}$ & $53 \%$ \\
3 & 2 & 10 & 110 & $24 \mathrm{~h}$ & $0.25 \mathrm{M}$ & $100 \%(73 \%)^{\mathrm{c}}$ \\
4 & 1 & 10 & 110 & $24 \mathrm{~h}$ & $0.25 \mathrm{M}$ & $72 \%$ \\
5 & 2 & 5 & 110 & $24 \mathrm{~h}$ & $0.25 \mathrm{M}$ & $100 \%$ \\
6 & 2 & 5 & 110 & $1 \mathrm{~h}$ & $0.25 \mathrm{M}$ & $100 \%$ \\
7 & 2 & 2 & 110 & $1 \mathrm{~h}$ & $0.25 \mathrm{M}$ & $50 \%$ \\
8 & 2 & 1 & 110 & $1 \mathrm{~h}$ & $0.25 \mathrm{M}$ & $46 \%$ \\
9 & 2 & 1 & 110 & $8 \mathrm{~h}$ & $0.25 \mathrm{M}$ & $58 \%$ \\
10 & 2 & 1 & 110 & $1 \mathrm{~h}$ & $1 \mathrm{M}$ & $68 \%$ \\
$\mathbf{1 1}$ & $\mathbf{2}$ & $\mathbf{1}$ & $\mathbf{1 1 0}$ & $\mathbf{1 h}$ & $\mathbf{5 M}$ & $\mathbf{1 0 0 \%}$ \\
12 & 2 & $-{ }^{\mathrm{e}}$ & 110 & $1 \mathrm{~h}$ & $5 \mathrm{M}$ & $0 \%$ \\
13 & - & 1 & 110 & $24 \mathrm{~h}$ & $5 \mathrm{M}$ & $0 \%$ \\
\hline
\end{tabular}

${ }^{a}$ Reaction conditions: 1a (1 mmol, 1 eq), (2a) (y eq), $\mathrm{HCo}\left(\mathrm{PMe}_{3}\right)_{4}(\mathrm{x} \mathrm{mol} \%$, with respect to the imine), toluene (c); ${ }^{b}$ Conversion determined by ${ }^{1} \mathrm{H}$ NMR of the crude material; ${ }^{\mathrm{c}} \mathrm{NH}_{3} \mathrm{BH}_{3}$ was used instead of $\mathrm{PhSiH}_{3}{ }^{\mathrm{d}} \mathrm{Co}\left(\mathrm{PMe}_{3}\right)_{4}$ was used as the catalyst; ${ }^{\mathrm{e}}$ With $4 \mathrm{~mol} \%$ of $\mathrm{PMe}_{3}$.

We chose ketimine 1a as our model substrate and phenylsilane (2a) as the hydrogen donor. By using 2 equivalents of hydrogen donor and $10 \mathrm{~mol} \%$ of $\mathrm{HCo}\left(\mathrm{PMe}_{3}\right)_{4}$ in toluene at room temperature, the reduction of the imine was observed but only in $6 \%$ conversion (Table 1, Entry 1). Reaction temperature has a significant impact on reaction efficiency, heating at $50{ }^{\circ} \mathrm{C}$ resulted in $53 \%$ conversion while a further increase to $110^{\circ} \mathrm{C}$ allowed complete conversion (Table 1 , Entries 1-3). Using $\mathrm{NH}_{3} \mathrm{BH}_{3}$ as a hydrogen donor instead of $\mathrm{PhSiH}_{3}$ allows the formation of the desired amine, albeit with a lower yield of $73 \%$ (Table 1, Entry 3). Lowering the amount of silane 
to 1 equivalent is detrimental as the conversion dropped to $72 \%$ (Table 1, Entry 4). On the other hand, the catalyst loading can be decreased from 10 to $5 \mathrm{~mol} \%$ and the reaction time reduced to 1 hour without loss of conversion (Table 1, Entries 5 and 6). Attempts to further reduce the catalyst loading to 2 or $1 \mathrm{~mol} \%$ results in decreased conversion even after 8 hours (Table 1, Entries 7-9). The key to reaching full conversion at $1 \mathrm{~mol} \%$ of catalyst, was doubling the reaction concentration from $0.25 \mathrm{M}$ to $5 \mathrm{M}$ (Table 1, Entries 8, 10 and 11). Therefore, we defined Entry 11, Table 1, as our optimal reaction conditions. Notably, $\mathrm{Co}\left(\mathrm{PMe}_{3}\right)_{4}$ is equally effective as a catalyst for this transformation. However, to allow reaction monitoring via NMR spectroscopy and as it is easier to characterize, we selected the cobalt(I) hydride $\mathrm{HCo}\left(\mathrm{PMe}_{3}\right)_{4}$ as the sole catalyst for the entirety of the investigation. To prove that trimethylphosphine was not the catalyst of our reaction, we conducted a test experiment in presence of $4 \mathrm{~mol} \%$ of trimethylphosphine instead of $\mathrm{HCo}\left(\mathrm{PMe}_{3}\right)_{4}$ that showed no conversion (Table 1, Entry 12). ${ }^{22}$ Moreover, no conversion occurred in the absence of silane, showing that it is the only source of hydrogen in our reaction medium (Table 1, Entry 13). Next, we screened the hydrogen donor efficiency of various silanes (2) in the reduction of phenylaldimine $4 \mathbf{b}$ (Figure 1, beige bar, $10 \mathrm{~mol} \%$ of catalyst) and phenylketimine $1 \mathbf{b}$ (Figure 1, yellow bar $10 \mathrm{~mol} \%$ of catalyst and orange bar $1 \mathrm{~mol} \%$ of catalyst). 


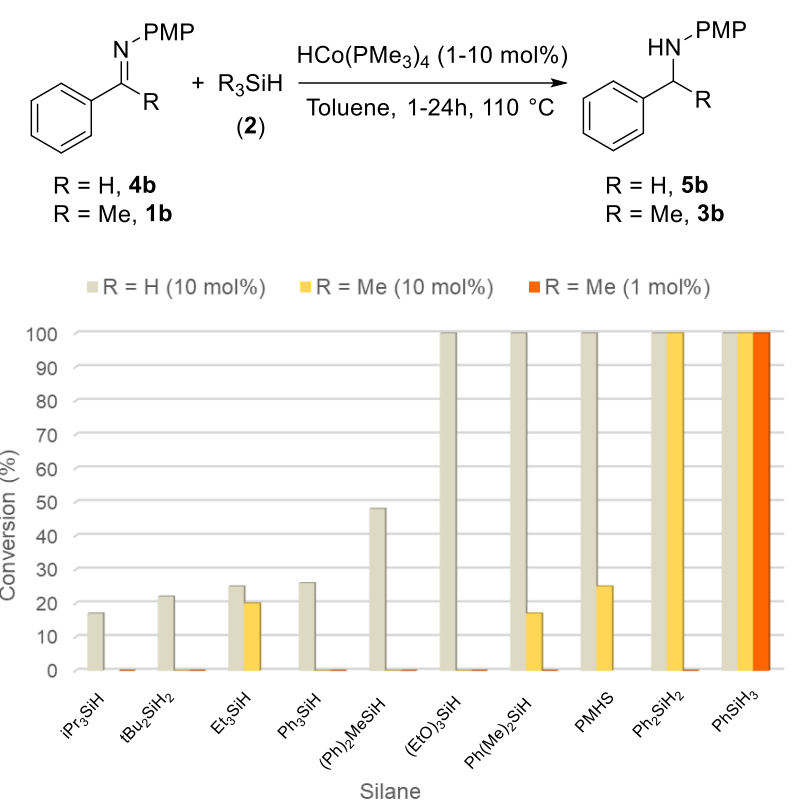

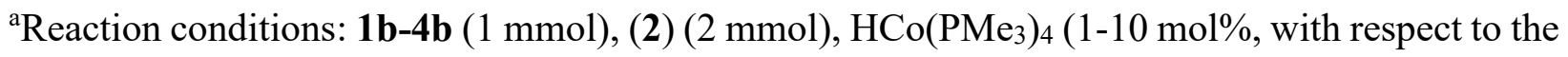
imine), toluene $(0.2 \mathrm{~mL}), 110^{\circ} \mathrm{C}, 24 \mathrm{~h}$ (beige and yellow bars) or $1 \mathrm{~h}$ (orange bar).

Figure 1. Screening of silanes (2) for the reduction of aldimine $\mathbf{4 b}$ and ketimine $\mathbf{1 b}^{\mathrm{a}}$

Almost all the silanes assayed can reduce aldimine $\mathbf{4 b}$, however alkyl and/or bulky ones are less efficient, with conversions below 50\%. Moreover, almost all of them are inefficient for the reduction of ketimine $\mathbf{1 b}$. Five silanes led to full aldimine reduction, among them, triethoxysilane and PMHS appeared as cheap and stable alternatives for aldimines hydrosilylation. However, they were not reactive enough with ketimines even at $10 \mathrm{~mol} \%$. Diphenylsilane and phenylsilane both allowed full conversion of both aldimine $\mathbf{4 b}$ and ketimine $\mathbf{1 b}$ at this loading. However, only phenylsilane maintains its efficiency at lower catalyst loadings. With optimal conditions in hand, we sought to explore the potential scope of this hydrosilylation reaction. Various imines bearing a p-methoxyphenyl substituent as the protecting group were first selected for stability reasons. 
Table 2. Hydrosilylation of aldimines $\mathbf{4}$ and arylketimines $\mathbf{1}^{\text {a }}$

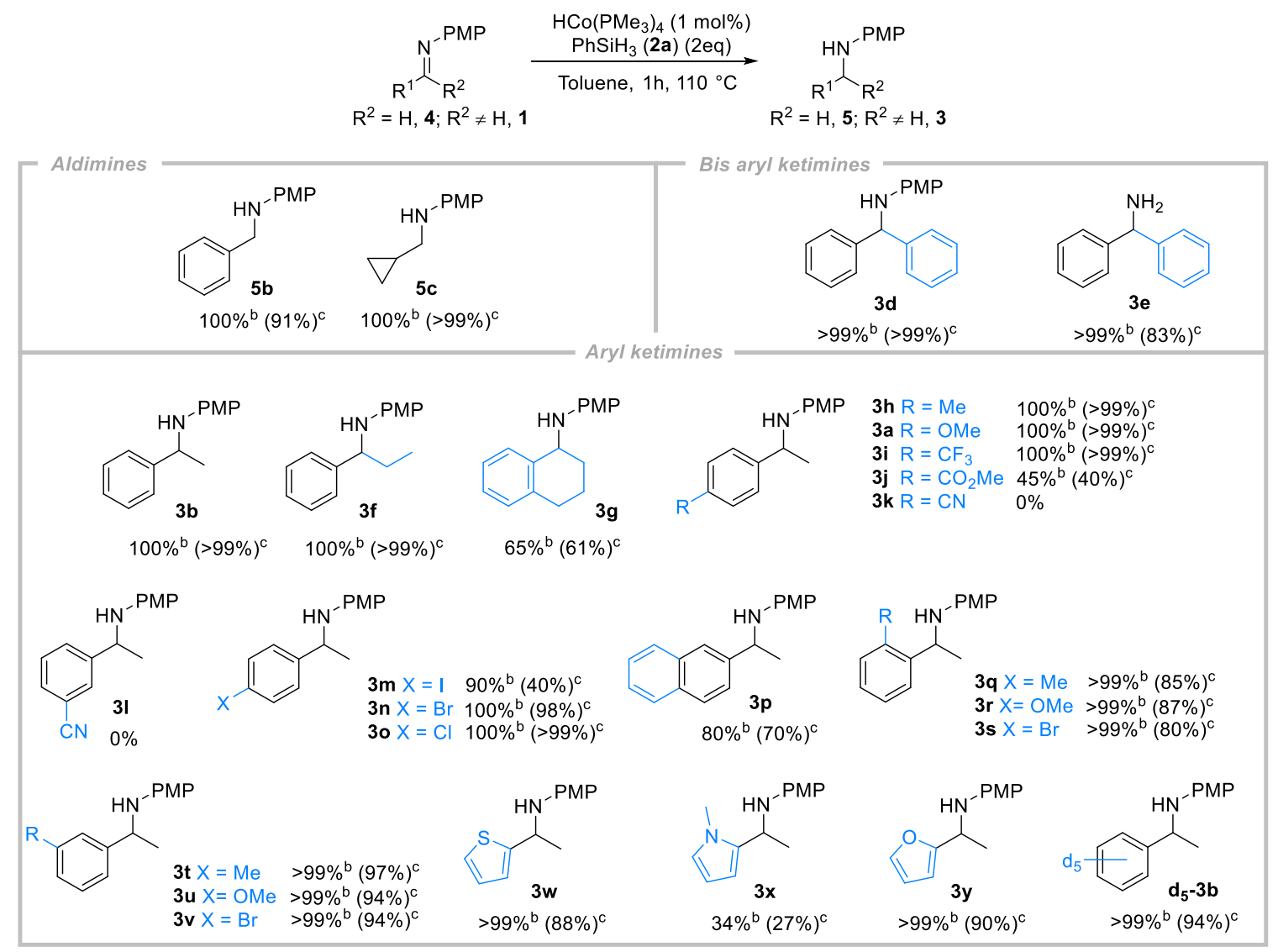

${ }^{\mathrm{a}} \mathbf{1}$ or 4 (1 mmol), (2a) $(2 \mathrm{mmol}), \mathrm{HCo}\left(\mathrm{PMe}_{3}\right)_{4}(1 \mathrm{~mol} \%$, with respect to the imine), toluene $(0.2 \mathrm{~mL}), 110{ }^{\circ} \mathrm{C}, 1 \mathrm{~h} ;{ }^{\mathrm{b}}$ Conversion determined by ${ }^{1} \mathrm{H}$ NMR analysis of the crude material; ${ }^{\mathrm{c}}$ Isolated yield.

As aldimines $\mathbf{4}$ are less challenging substrates based on literature precedents, we chose to test only one aryl aldimine and one alkyl aldimine. As shown in the silane scope study, phenylaldimine 4b was completely hydrosilylated and the corresponding amine $\mathbf{5 b}$ can be isolated in $91 \%$ yield after work-up (Figure 1 and Table 2). Unsurprisingly, cyclopropylaldimine $\mathbf{4 c}$ was easily reduced forming the corresponding amine 5c, after work up, in quantitative yield. Bis-aryl ketimines such as $\mathbf{1 d}$ and $1 \mathbf{e}$ are also viable substrates affording amines $\mathbf{3 d}$ and $\mathbf{3 e}$ in quantitative and $83 \%$ yield, respectively. It is worth mentioning that the absence of a protecting group on imine 1e has no 
influence on its reactivity. By varying the substitution pattern at the alkyl moiety, we showed that imines derived from propiophenone $1 \mathbf{f}$ and tetralone $\mathbf{1 g}$ also yielded the desired amines in quantitative and $61 \%$ yield, respectively. The reaction proceeded in good yields for parasubstituted aryl imines. Electron-donating $(\mathrm{OMe}, \mathbf{1 a})$, neutral $(\mathrm{Me}, \mathbf{1 h})$, and electron-withdrawing groups (e.g., $\left.\mathrm{CF}_{3}, \mathbf{1 i}\right)$ were all tolerated and led to quantitative yields. Competitive experiments and DFT calculations were performed to detect any electronic effect depending on the substitution of the aromatic rings of the imines (see the Mechanistic Considerations part). Introduction of a methylester substituent at this position seems to have a deleterious effect on reactivity since only $45 \%$ conversion was obtained together with the recovery of the starting material $\mathbf{1} \mathbf{j}$. Introducing a nitrile onto the aromatic ring of the starting imine is completely detrimental to the reaction as $1 \mathbf{k}-$ I were fully recovered. Two hypotheses can be proposed: first, an electronic effect of the cyano substituent contributed to this unexpected lack of reactivity towards our catalyst; second, coordination of the Lewis basic nitrile substituent may poison the cobalt catalyst. To confirm the latter proposition, we ran a competitive experiment in acetonitrile (see Scheme S1) that demonstrated the inhibition of the catalyst in the presence of a nitrile moiety.

para-halogenated aryl imines $\mathbf{1} \mathbf{m}-\mathbf{o}$ also gave the desired amine in quantitative yield for chlorine and bromine substitution, and moderate yield for the iodine group that may be involved in oxidative addition side reactions. ortho- and meta-substituted imines 1q-v with methyl, methoxy or bromine groups were well tolerated under reaction conditions and the corresponding amines 3q-v were obtained in yields ranging from $80 \%$ to $97 \%$. Heteroaryl rings such as thiophene, $N$ methylpyrrole, or furane in imines $\mathbf{1} \mathbf{w}-\mathbf{y}$ are compatible with our catalytic system and the amines 3w-y are obtained in $88 \%, 27 \%$ and $90 \%$ yield, respectively. Finally, the deuterated analog of imine $1 \mathbf{b}$ can be reduced in $94 \%$ yield. Importantly, the integrity of the perdeuterated aryl of the 
amine was maintained, showing that, contrary to our previous study, ${ }^{19 \mathrm{c}}$ no $\mathrm{C}-\mathrm{H}$ activation mechanism or intermediate is involved here.

Table 3. Hydrosilylation of aliphatic ketimines and $\alpha, \beta$-unsaturated ketimines. ${ }^{\text {a }}$
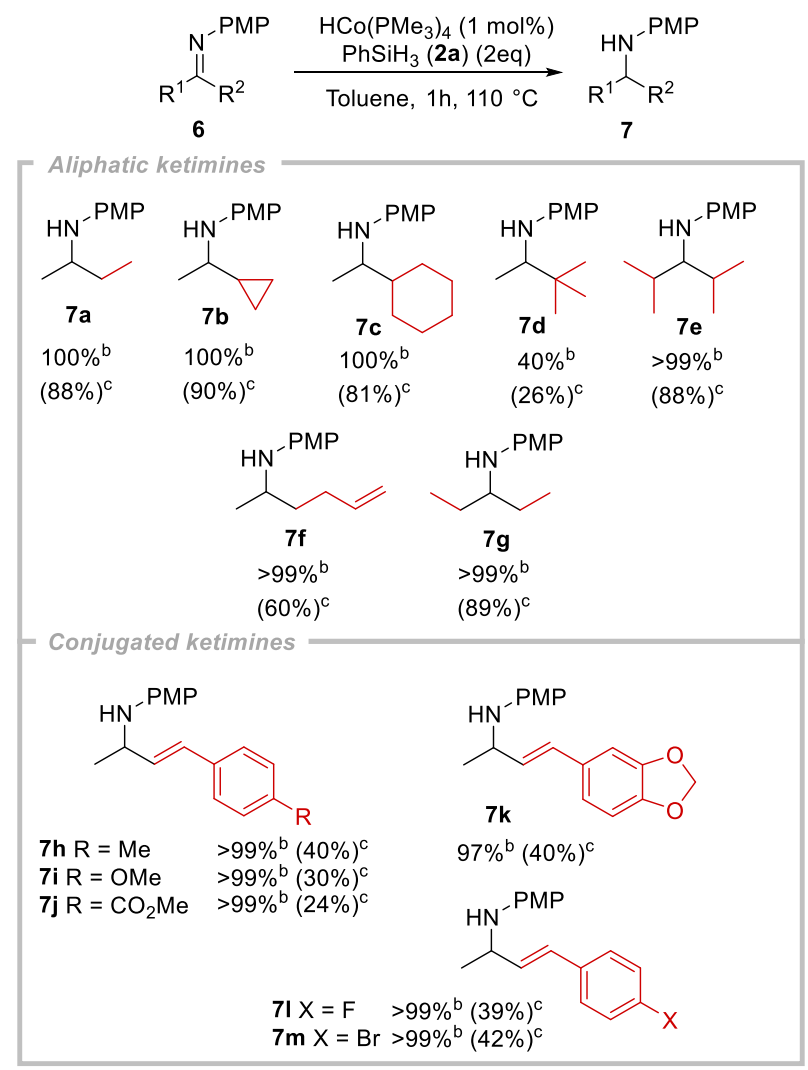

${ }^{a} 6(1 \mathrm{mmol}),(\mathbf{2 a})(2 \mathrm{mmol}), \mathrm{HCo}\left(\mathrm{PMe}_{3}\right)_{4}(1 \mathrm{~mol} \%$, with respect to the imine $)$, toluene $(0.2 \mathrm{~mL})$, $110{ }^{\circ} \mathrm{C}, 1 \mathrm{~h}$; ${ }^{b}$ Conversion determined by ${ }^{1} \mathrm{H}$ NMR analysis of the crude material. ${ }^{\mathrm{c}}$ Isolated yield.

We then turned our attention towards the more challenging aliphatic ketimines and conjugated imines scarcely described in the literature (Table 3). To our delight aliphatic ketimines 6a-g bearing ethyl, cyclopropyl, isopropyl, cyclohexyl, and homoallyl substituents proceeded efficiently under our optimal conditions and afforded the corresponding amines $\mathbf{7 a - g}$ in good yields. Only compound $\mathbf{6 d}$ bearing a tert-butyl group presented lower conversion most likely due to steric hindrance; the corresponding amine $7 \mathbf{d}$ was obtained in $26 \%$ with recovery of the starting imine 6d. On the contrary, ketimine 6e substituted by two isopropyl groups does not suffer from 
any loss of reactivity and the amine $7 \mathbf{e}$ can be isolated in good yield (88\%). Finally, imine $\mathbf{6 f}$ bearing a terminal alkene on the alkyl chain provided the desired amine $7 f$ in $60 \%$ yield, showing no reduction of the alkene moiety. Thus, we proceeded with the hydrosilylation of $\alpha, \beta$-unsaturated ketimines 6h-m. All worked perfectly with full conversion and selectivity. However, given no concomitant reduction of the alkene, the desired allylic amines are prone to degradation and the isolated yields are low (24-42\%).

Finally, we tested our catalytic system for the challenging reduction of aromatic heterocycle quinoline (8a) (Scheme 2). ${ }^{23}$ Pleasingly, under the same reaction conditions, we observed complete conversion of quinoline and the formation of 1,2-dihydroquinoline 9a in 87\% yield. Notably, the selectivity of this reduction is excellent, as 1,2-dihydroquinoline 9a was formed as a single regioisomer, with only traces of tetrahydroquinoline arising from over reduction.

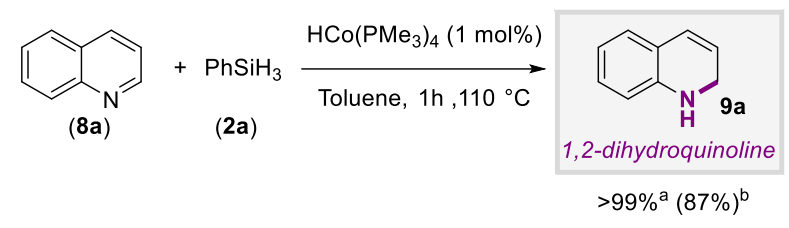

${ }^{\mathrm{a} C}$ Conversion determined by ${ }^{1} \mathrm{H}$ NMR analysis of the crude material; ${ }^{\mathrm{b}}$ Isolated yield Scheme 2. Selective 1,2-reduction of quinoline (8a)

Our reaction scope (Tables 2 and 3) demonstrates the robustness of our procedure. Importantly, no change to catalyst loading or reaction time was necessary to reach almost full conversion for each substrate, which is often not the case in the literature. Finally, we investigated the compatibility of various imine protecting groups (see Table 4). We previously demonstrated that free imine 1e, with no protecting group, could be efficiently hydrosilylated under these conditions (vide supra Table 2). 
Table 4. Scope of the imine protecting group ${ }^{\mathrm{a}}$

\begin{tabular}{|c|c|c|c|c|}
\hline \multirow{2}{*}{\multicolumn{2}{|c|}{$\begin{array}{l}P_{R}^{N^{-P G}} \\
R=H, 4 \\
R=M e, 1\end{array}$}} & \multirow{2}{*}{\multicolumn{2}{|c|}{$\begin{array}{c}\mathrm{HCo}\left(\mathrm{PMe}_{3}\right)_{4}(1 \mathrm{~mol} \%) \\
\mathrm{PhSiH}_{3}(2 \mathrm{a})(2 \mathrm{eq})\end{array}$}} & \multirow{2}{*}{$\begin{array}{l}\mathrm{Ph}_{\mathrm{R}} \\
\mathrm{R}=\mathrm{H}, \mathbf{5} \\
\mathrm{R}=\mathrm{Me}, 3\end{array}$} \\
\hline & & & & \\
\hline Entry & $\overline{\mathbf{R}}$ & $\overline{P G}$ & Conversion (\%) & Yield (\%) \\
\hline 1 & $\mathrm{H}$ & PMP 5b & $>99$ & 91 \\
\hline 2 & $\mathrm{H}$ & $\mathrm{Ph} 5 \mathbf{d}$ & $>99$ & 92 \\
\hline 3 & $\mathrm{H}$ & Bn $5 e$ & $>99$ & 82 \\
\hline 4 & $\mathrm{H}$ & $\mathrm{SO}_{2} \mathrm{Ph} \mathbf{5 f}$ & 80 & 63 \\
\hline 5 & $\mathrm{H}$ & Ts $5 \mathbf{g}$ & 60 & 47 \\
\hline 6 & $\mathrm{H}$ & ${ }^{t} \mathrm{Bu} \mathbf{5 h}$ & 63 & 55 \\
\hline 7 & $\mathrm{H}$ & TMS 5i & $>99$ & degradation \\
\hline 8 & $\mathrm{H}$ & Boc 5j & $>99$ & degradation \\
\hline 9 & $\mathrm{Me}$ & $c \operatorname{Pr} \mathbf{3 b a}$ & 70 & 63 \\
\hline 10 & $\mathrm{Me}$ & $\mathrm{Ph} \mathbf{3 b b}$ & $>99$ & 99 \\
\hline 11 & $\mathrm{Me}$ & $p-\mathrm{CF}_{3} \mathrm{Ph} \mathbf{3 b c}$ & $>99$ & 98 \\
\hline
\end{tabular}

${ }^{\mathrm{a}} 1$ or $4(1 \mathrm{mmol})$, (2a) ( $\left.2 \mathrm{mmol}\right), \mathrm{HCo}\left(\mathrm{PMe}_{3}\right)_{4}(1 \mathrm{~mol} \%$, with respect to imine), toluene $(0.2 \mathrm{~mL})$, $110{ }^{\circ} \mathrm{C}, 1 \mathrm{~h} ;{ }^{\mathrm{b}} \mathrm{Conversion}$ determined by ${ }^{1} \mathrm{H}$ NMR analysis of the crude material; ${ }^{\mathrm{C}}$ Isolated yield.

Using commercially available aldimines $(\mathbf{4 d}-\mathbf{j})$ we showed that aryl or benzyl protected aldimines (4d) and (4e) led to quantitative conversion and good isolated yields ( $92 \%$ and $82 \%$, respectively) (Table 4, Entries 2 and 3). Arylsulfonyl protected imines such as (4f) and the tosyl (Ts) analog (4g) were less reactive and lower conversions and yields were observed (Table 4, Entries 4 and 5). In these cases we can postulate a potential ligation between the sulfonyl group and the catalyst that may slow down the reaction. Alkyl groups, such as tert-butyl, can be used (Table 4, Entry 6), albeit with a moderate $55 \%$ yield, probably due to the steric hindrance imposed. On the contrary, TMSand Boc-protected aldimines $(\mathbf{4 i )}$ and $(\mathbf{4 j})$ are not compatible with our reaction conditions and full degradation was observed (Table 4, Entries 7 and 8). Finally, ketimines $\mathbf{1 b a}, \mathbf{1 b b}$ and $\mathbf{1 b c}$ bearing 
a cyclopropyl, a phenyl and a para- $\mathrm{CF}_{3}$-phenyl protecting group, respectively, were all reactive and gave the desired amines $\mathbf{3 b a}, \mathbf{3 b b}$ and $\mathbf{3 b c}$ in 63\%, 99\% and 98\% isolated yields, respectively (Table 4, Entries 9-11).

\section{MECHANISTIC CONSIDERATIONS}

In order to gain more mechanistic information, we monitored the evolution of the reaction in situ via ${ }^{1} \mathrm{H}$ NMR spectroscopy in a J. Young tube. For this experiment, we selected reaction conditions (Table 1, entry 5) with a concentration and a catalyst loading compatible with ${ }^{1} \mathrm{H}$ NMR spectroscopic analysis.
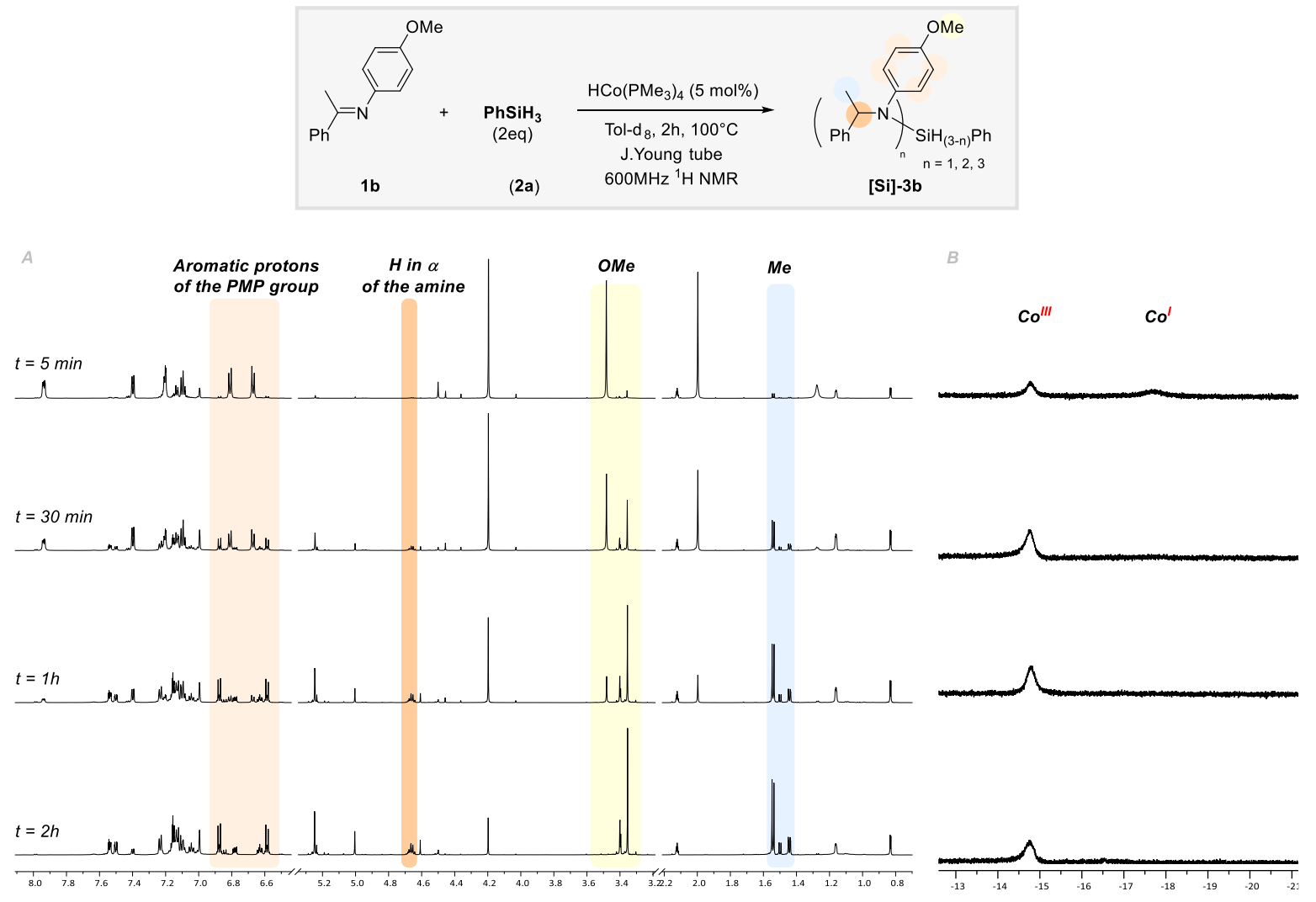

Figure 2. ${ }^{1} \mathrm{H}$ NMR spectrum (toluene- $\mathrm{d}_{8}, 600 \mathrm{MHz}, 373 \mathrm{~K}$ ) evolution of the hydrosilylation reaction. A. ${ }^{1} \mathrm{H}$ area between $\delta 0.5$ and $8 \mathrm{ppm}, \mathrm{B} .{ }^{1} \mathrm{H}$ area between $\delta-21$ and $-13 \mathrm{ppm}$. 
After 5 minutes, the hydride quintet at $\delta-17.31 \mathrm{ppm}$ (Figure 2, area B), arising from the starting complex $\mathrm{HCo}\left(\mathrm{PMe}_{3}\right)_{4}$, has almost completely disappeared (see Supporting Information Figure S10 for more information) to form another complex with a hydride shifted at $\delta-14.76 \mathrm{ppm}$. Presumably, this new complex is obtained by oxidative addition of the $\mathrm{HCo}\left(\mathrm{PMe}_{3}\right)_{4}$ complex on $\mathrm{PhSiH}_{3}$ (2a) to generate a new cobalt(III) specie (vide infra for studies dedicated to oxidative addition). The reaction is complete after 2 hours, as determined by observing the ${ }^{1} \mathrm{H}$ NMR spectrum. It is important to note that the products formed are silylated amines: this rules out a hydrogenation pathway and confirms the hydrosilylation process. Since we used $\mathrm{PhSiH}_{3}$ (2a) we obtained a mixture of the aminosilane, the diaminosilane and some oligomers. However, after classical filtration on a pad of silica gel flushed with ethyl acetate, the free amine $\mathbf{3 b}$ was obtained as the sole product (see Supporting Information Figure S11). Finally, the apparition of the quartet at $\delta 4.65 \mathrm{ppm}$, corresponding to the proton in the $\alpha$ position of the amine, shows that no incorporation of silane occurs at this position. It is worth mentioning that no hydride characteristic of a cobalt(I) complex was observed after 2 hours (Figure 2 area B). We also carried out deuteration experiments to rule out any enamine tautomers of ketimine. ${ }^{24}$ Therefore, by using commercially available deuterated diphenylsilane $\left(\mathrm{d}_{2}-\mathbf{2} \mathbf{b}\right)$ under our standard conditions, we observed the full incorporation of deuterium at the $\alpha$ position of the amine (Scheme 3a). This result confirms a direct hydrosilylation of the ketimines. Moreover, when using a 1/1 mixture of deuterated and nondeuterated silane, we obtained a $42 / 58$ mixture of the deuterated amine $\mathbf{d - 3 b}$ and the nondeuterated one $\mathbf{3 b}$ (Scheme 3b). The KIE of value 1.4 observed close to unity may suggest that the $\mathrm{Si}-\mathrm{H}$ bond cleavage is not involved in the rate determining step of the reaction and that the formation of the $\mathrm{C}-\mathrm{H}$ bond in the $\alpha$ position of the amine is a non-reversible step. ${ }^{25}$ 


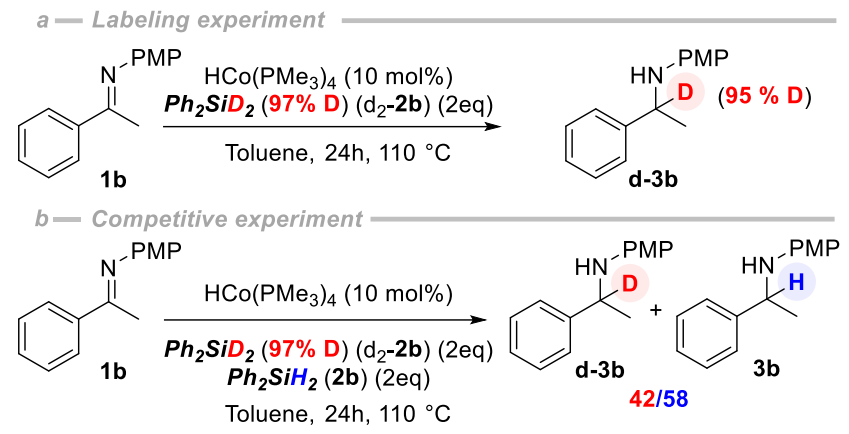

Scheme 3. a) Labeling experiment and b) Competitive experiment with $\mathrm{Ph}_{2} \mathrm{SiD}_{2}\left(\mathrm{~d}_{2}-\mathbf{2 b}\right)$

As previously mentioned, we discovered during ${ }^{1} \mathrm{H}$ NMR spectroscopic monitoring, that a new cobalt complex rapidly formed in presence of the silane. We postulated the formation of cobalt(III) complex by oxidative addition of the silane as observed in our previous study on alkyne hydrosilylation. ${ }^{19 \mathrm{e}}$ To confirm our hypothesis we successfully isolated four silyl dihydride cobalt (III) complexes resulting from the oxidative addition of various silanes: $\mathrm{PhSiH}_{3}(\mathbf{2 a}), \mathrm{Ph}_{2} \mathrm{SiH}_{2}$ (2b) ${ }^{26} \mathrm{Ph}_{3} \mathrm{SiH}(\mathbf{2 c})$ and $(\mathrm{EtO})_{3} \mathrm{SiH}(\mathbf{2 d})$ on $\mathrm{HCo}\left(\mathrm{PMe}_{3}\right)_{4}$ at $80{ }^{\circ} \mathrm{C}$. The characterization of these species by ${ }^{1} \mathrm{H}$ NMR spectroscopy revealed a common tendency of the hydride peak to shift from $\delta-17.31 \mathrm{ppm}$ for the $\mathrm{HCo}\left(\mathrm{PMe}_{3}\right)_{4}$ complex to $\delta-14.76,-14.66,-14.79$ and $-15.28 \mathrm{ppm}$, respectively (Figure 3). Moreover, the integration evolves from $1 \mathrm{H}$ for the starting $\mathrm{HCo}\left(\mathrm{PMe}_{3}\right)_{4}$ cobalt complex $\mathbf{C o - I}$ to $2 \mathrm{H}$ for the cobalt(III) adduct $\mathbf{C o S i}$, together with the loss of one phosphine. These observations confirm the stoichiometric interaction between the silane and the cobalt(I) complex, probably via oxidation addition. Notably, heating these complexes overnight at $80{ }^{\circ} \mathrm{C}$ or $100{ }^{\circ} \mathrm{C}$ does not allow recovery of the starting $\mathrm{HCo}\left(\mathrm{PMe}_{3}\right)_{4}$ complex, suggesting non-reversibility of the oxidative addition step. 


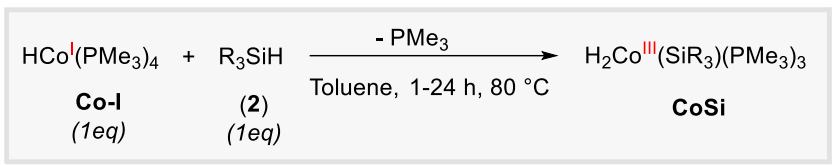

$\mathrm{H}_{2} \mathrm{Co}^{\prime \prime \prime}\left(\mathrm{SiH}_{2} \mathrm{Ph}\right)\left(\mathrm{PMe}_{3}\right)_{3}$ CoSi-a
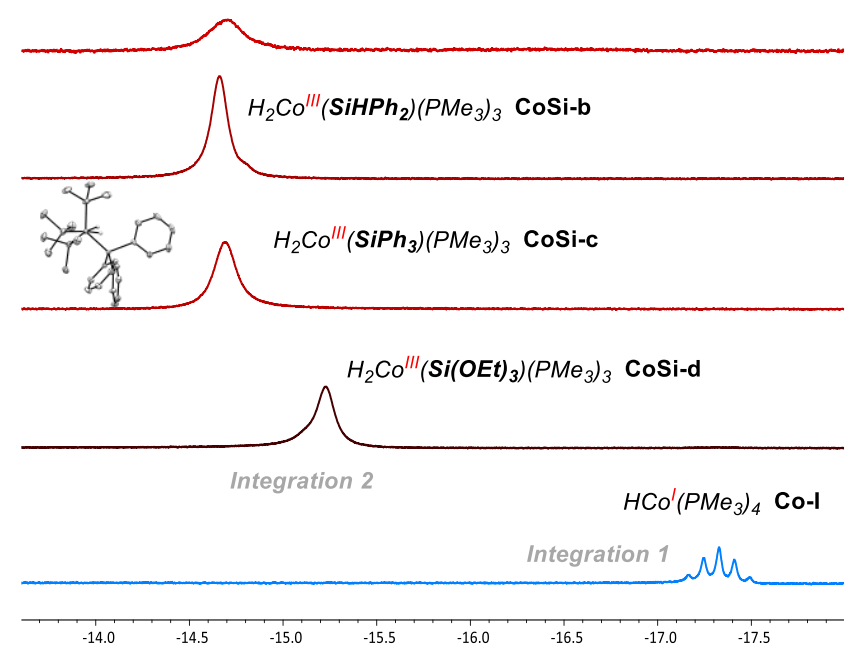

Figure 3. ${ }^{1} \mathrm{H}$ NMR spectrum (toluene- $\mathrm{d}_{8}, 400 \mathrm{MHz}$ ) focused on the cobalt hydride area for the complexes CoSi-a, CoSi-b, CoSi-c, CoSi-d and Co-I

To our delight, we were able to obtain suitable crystals for X-ray diffraction analysis for triphenylsilyl dihydride cobalt (III) complex 2c and confirmed the exact structure of these new cobalt(III) complexes CoSi (Figure 4). 

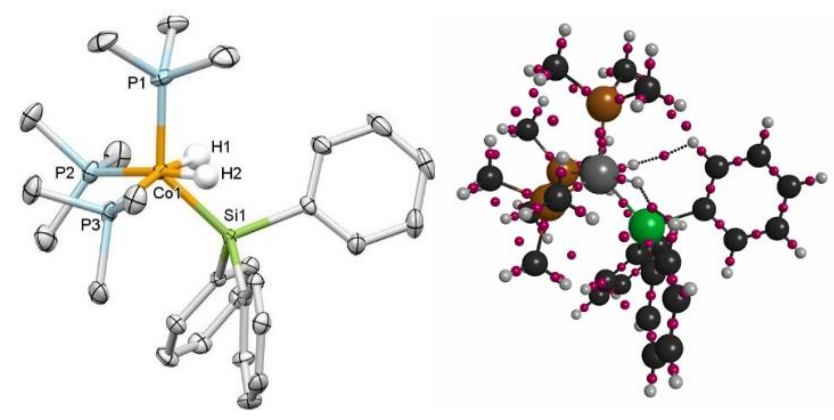

Figure 4. (Left) Solid-state molecular structure of $\mathrm{CoH}_{2}\left(\mathrm{SiPh}_{3}\right)\left(\mathrm{PMe}_{3}\right)_{3} \mathbf{C o S i}$-c; Hydrogen atoms except the ones on Co and Si have been omitted for clarity. (Right) AIM analysis based on DFT calculations, purple balls indicate bond critical points.

At this point, The solid-state molecular structure of CoSi-c reveals an octahedron typical for a cobalt(III) complex, however the geometry is quite distorted. Complete oxidative addition seems to have occurred, as $\mathrm{Si}-\mathrm{H}$ bond distances are longer than $2.00 \AA$. This is further confirmed by the short $\mathrm{Co}-\mathrm{H}$ bond lengths of 1.40 and $1.33 \AA$. Compared to previously described dihydridosilylcobalt(III) complexes, ${ }^{27}$ the distortion suggests an agostic interaction between the hydrogens and the silicon atoms. However, a NCIPLOT analysis based on DFT calculations reveals no strong dispersive interactions between the two hydrogens bonded to the cobalt and the silicon atoms. Interestingly, dispersion occurs between these hydrogen atoms and the phenyl groups of the silane (see Figure 4 right, dashed bonds). The Co-Si bond length of $2.24 \AA$ is significantly longer than a possible silylene dihydride as shown recently by Tilley. ${ }^{28}$

We were wondering if these silyl cobalt(III) dihydride complexes were the real active catalysts in the reaction. Using two isolated cobalt(III) dihydride complexes CoSi-a and CoSi-d we first ran stoichiometric experiments in a J. Young NMR tube with imine $\mathbf{1 b}$ without addition of silane (Figure 5a1 and 5a2). We observed that the desired amine $\mathbf{3 b}$ was obtained in $50 \%$ yield using the 
complex synthesized from $\mathrm{PhSiH}_{3}$ (2a). This suggests that $\mathbf{C o S i - a}$ could indeed be the catalyst of our reaction. Moreover, the same isolated complex CoSi-a used in a catalytic amount (1 mol\%) in the presence of $\mathrm{PhSiH}_{3}$ (2a) allowed full conversion to the desired amine, confirming this hypothesis (Figure 5b3 right). On the other hand, no amine was formed using the analog CoSi-d arising from $(\mathrm{EtO})_{3} \mathrm{SiH}(\mathbf{2 d})$. This observation is in agreement with the catalytic approach as no ketimine reduction was observed in the presence of an excess of triethoxysilane as the reducing agent (Figure 1 and Figure 5b1-left). It is interesting to note that, starting from a catalytic amount of the isolated complex CoSi-d, however this time, in the presence of an excess of $\mathrm{PhSiH}_{3}$ (2a), reactivity is restored and full conversion is achieved (Figure $5 \mathrm{~b} 2$ right). Finally, we performed the reverse reaction (Figure 5b3). With a catalytic amount of CoSi-a in presence of an excess of $(\mathrm{EtO})_{3} \mathrm{SiH}(\mathbf{2 c})$ no reaction was observed (Figure $5 \mathrm{~b} 3$ left) but a post-addition of $\mathrm{PhSiH}_{3}(\mathbf{2 a})$ restored the reactivity and total conversion was observed (Figure $5 \mathrm{~b} 3$ bottom). These last results suggest that $\mathrm{PhSiH}_{3}(\mathbf{2 a})$ is necessary for the reaction to turnover, probably through sigma-bond metathesis and not reductive elimination. ${ }^{29}$ This is also confirmed by the fact that we never observed during the course of these reactions the (re)formation of any cobalt(I) species (see Figure 2 area $\mathrm{B})$. 


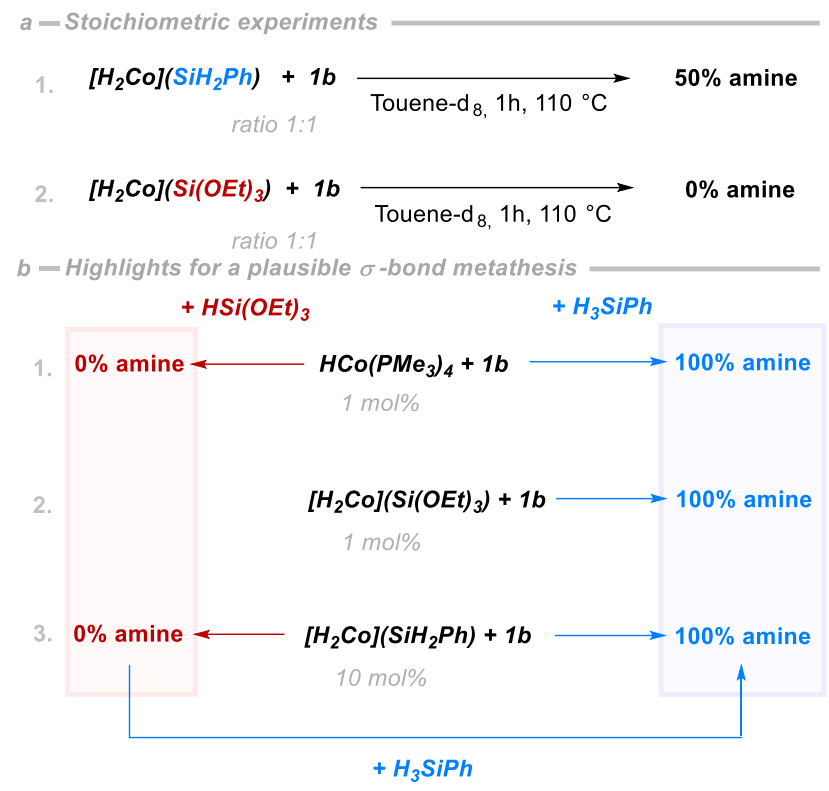

Figure 5. Reactivity of silyl cobalt(III) dihydride complexes CoSi-a and CoSi-d in presence of silanes (2a) and (2d). a) Stoichiometric experiments; b) Highlights for a plausible $\sigma$-bond metathesis

Kinetic studies were then conducted. ${ }^{29}$ The oxidative addition step was studied by monitoring the disappearance of $\mathrm{HCo}\left(\mathrm{PMe}_{3}\right)_{4}$ Co-I over time by ${ }^{1} \mathrm{H}$ NMR spectroscopy in the presence of an excess of phenylsilane (2a). The linear behavior of $\ln \left(\left[\mathrm{Co}^{\mathrm{I}}\right] /\left[\mathrm{Co}^{\mathrm{I}}\right]_{0}\right)$ vs time and the linear plot of $k_{a p p}$ vs [Si] indicates that the first step of the catalytic cycle exhibits a first-order dependence on Co-I and on (2a) (see Figures S12 and S13). The catalytic hydrosilylation of imines was then studied by monitoring the consumption of the imine over time. The decay of $\mathbf{1 b}$ over time was exponential (Figure 6a). All plots of $\ln [\mathbf{1 b}]$ vs time were linear indicating that the reaction has a first order dependence on 1b (Figure $6 \mathrm{~b}$ and Figures S14 and S15). We then varied the concentration of phenylsilane (2b) and catalyst Co-I independently. Linear plots of $k_{o b s}$ vs [Si] (Figure 6c) and $k_{o b s}$ vs $[\mathbf{C o I}]$ (Figure 6d) were obtained. We concluded that the reaction rate exhibits a first-order dependence on both (2b) and Co-I. To go further, kinetics studies were 
conducted using CoSi-a as the catalyst. By varying its concentration, a linear plot of $k_{o b s} \mathrm{Vs}\left[\mathrm{Co}^{\mathrm{III}}\right]$ (Figure 6e) was obtained, revealing that the reaction exhibits a first-order dependence whether starting from Co-I or from CoSi-a.
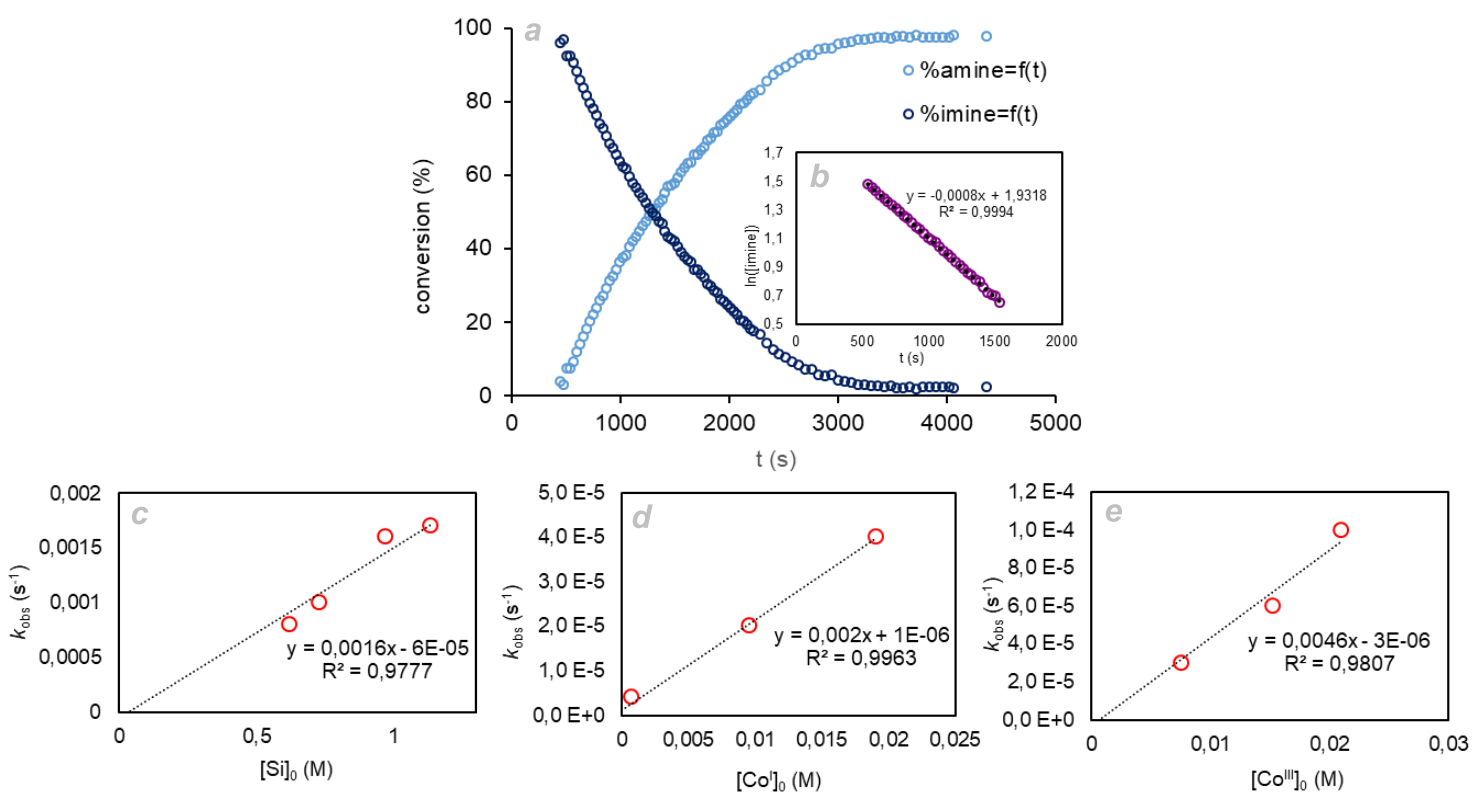

Figure 6 a) Reaction profile of the hydrosilylation of $\mathbf{1 b}$ using phenylsilane (2a), Co-I as catalyst and 1,3,5-trimethoxybenzene as internal standard at $80{ }^{\circ} \mathrm{C}$ in toluene- $d^{8}$. b) Plot of $\ln [\mathbf{1 b}]$ vs time using the conditions of Figure 6a. c) Plot of $k_{o b s}$ vs $[\mathbf{2} \mathbf{a}]_{0}$. All the $k_{o b s}$ were obtained from the slope of $\ln [\mathbf{1 b}]$ vs time plots. d) Plot of $k_{o b s}$ vs $[\mathbf{C o}-\mathbf{I}]_{0}$. All the $k_{o b s}$ were obtained from the slope of $\ln [\mathbf{1 b}]$ vs time plots. e) Plot of $k_{o b s}$ vs $[\mathbf{C o S i - a}]_{0}$. All the $k_{o b s}$ were obtained from the slope of $\ln [\mathbf{1 b}]$ vs time plots (see Figures S12 to S20).

Based on experimental observations, we can make some mechanistic assumptions. ${ }^{30}$ One possibility could be that the reaction involves a radical mechanism. In fact, several radical additions onto imines have been described during the last two decades. ${ }^{31}$ Radical pathways, through hydrogen atom transfer (HAT), are normally proposed in the presence of an alkene and a metal hydride, ${ }^{32}$ the group of Chirik recently described that HAT mechanism can also occur using 
a cobalt hydride complex under thermal conditions. ${ }^{33}$ In our case, we ruled out a mechanism based on a radical pathway. Indeed, we chose aldimine $4 \mathbf{c}$, ketimines $1 \mathbf{x}$ and $\mathbf{6 b}$ bearing a cyclopropyl radical-clock substituent in some critical positions (on the nitrogen atom or in the alpha position). Whatever the substrate, we never observed the formation of compounds arising from the ringopening of the cyclopropyl unit, typical of the formation of a radical in this position. ${ }^{34}$ Moreover, when imine $\mathbf{6 f}$ incorporating a pendent alkene moiety was evaluated in this reaction, no cyclization occurred either.

Additional mechanistic information was elucidated by performing DFT calculations using the Turbomole (version 6.5) suite of programs (Figure 7). The level of calculations was chosen to follow previous calculations conducted on $\mathrm{HCo}\left(\mathrm{PMe}_{3}\right)_{4}$ : $\mathrm{B} 3 \mathrm{LYP}$ as functional; complemented by the $\mathrm{D} 3$ dispersion scheme and using the def2-SV(P) basis set for describing orbitals.

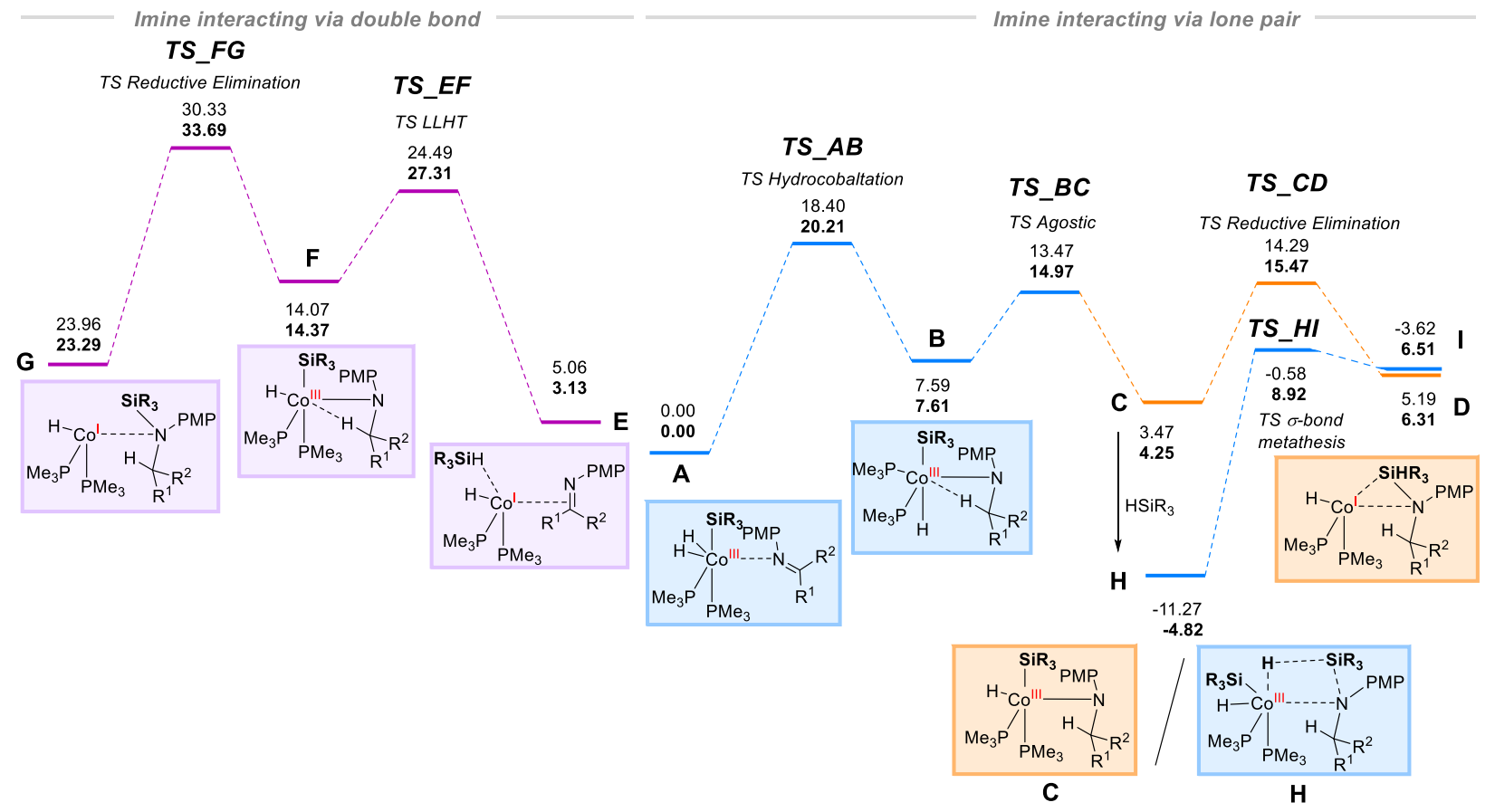

Figure 7. DFT calculated potential energy surfaces (in $\mathrm{kcal}^{\mathrm{mol}}{ }^{-1}$ ) of the cobalt-catalyzed hydrosilylation of imines via the interaction with the double bond (on the left) and via the 
interaction with the lone pair (on the right). Values in normal and bold fonts correspond respectively to the enthalpy and Gibbs free energies

Firstly, the cobalt complex $\mathrm{HCo}\left(\mathrm{PMe}_{3}\right)_{4} \mathrm{Co}$-I seems to be a pre-catalyst in the reaction. Due to the excess of silane (200 equivalents compared to the catalyst), a fast oxidative addition with the loss of one trimethylphosphine occurs to form the silylated cobalt(III) complex CoSi. A second trimethylphosphine is then exchanged with the imine, and at this stage, two different ligations of the cobalt to the imine can be envisioned: a ligation through the lone pair of the imine to give intermediate $\mathbf{A}$ or a $\pi$-ligation to generate $\mathbf{E}$ (Figure 7). Calculated structure $\mathbf{E}$ corresponds in fact to a complex in which the silane has not yet reacted with the cobalt center through oxidative addition. Thus it seems that the $\mathrm{H}_{2} \mathrm{Co}(\mathrm{III})$ complex prefers coordination of the imine through the lone pair of the nitrogen. Three mechanistic possibilities can be now envisaged: a ligand to ligand hydrogen transfer (LLHT in purple) from the $\pi$-adduct intermediate $\mathbf{E}$; or from the lone pair adduct A, a hydrocobaltation (in blue) or cobaltasilylation (not shown). The first mechanism that we can rule out based on calculations is cobaltasilylation: attempts to localize a transition state for this process gave barriers in the range of $50 \mathrm{kcal} / \mathrm{mol}$. On the other hand, it is possible to localize a transition state from $\mathbf{A}$ corresponding to the hydrocobaltation process (TS_AB), with a barrier of $20.21 \mathrm{kcal} / \mathrm{mol}$. The intermediate $\mathbf{B}$ obtained is characterized, in particular, by an agostic interaction between the transferred hydrogen and the cobalt center. To perform reductive elimination, it is necessary to first break this agostic interaction (TS_BC, barrier of $14.97 \mathrm{kcal} / \mathrm{mol}$ ) to reach intermediate $\mathbf{C}$ which can undergo reductive elimination (in orange) with a barrier of $15.47 \mathrm{kcal} / \mathrm{mol}$ (TS_CD). It should be noted that the formation of product $\mathbf{D}$ is endothermic, however probably compensated by the numerous phosphines present in solution and not modelled here. Another possible termination of the catalytic cycle can also be a sigma-bond metathesis 
between intermediate $\mathbf{B}$ and another silane molecule (in blue). Again, it is first necessary to break the agostic interaction to reach intermediate $\mathbf{H}$ and replace this interaction by the second silane. Since the postulated mechanism of sigma-bond metathesis involves a second silane, it was necessary to adjust our computational protocol to take into account the bimolecularity of the process. The remaining part of the computational exploration is unaffected by this modification. Namely, following the idea of Wertz ${ }^{35}$ and Ziegler, ${ }^{36}$ the gas-phase calculated entropies were divided by two in order to mimic the solvation process occurring during the course of the reaction. Hence, the approach of the second silane has a lower entropic cost reflecting its presence in large concentration. With this correction, we found that the metathesis mechanism has a barrier of 13.74 $\mathrm{kcal} / \mathrm{mol}$. Since the binding of the second silane is exothermic by $9.07 \mathrm{kcal} / \mathrm{mol}$ (from $\mathbf{C}$ to $\mathbf{H}$ ), this process is much more favorable than direct reductive elimination that requires, in total, 20.29 $\mathrm{kcal} / \mathrm{mol}$ from intermediate $\mathbf{H}$. The other mechanistic possibility that we envisaged is to start from $\mathbf{E}$ and to perform imine reduction by avoiding oxidative addition on the metal. In that case, the mechanism would be reminiscent of the one we previously determined for $\mathrm{C}-\mathrm{H}$ activation (i.e. Ligand to Ligand Hydrogen Transfer). ${ }^{19 \mathrm{c}}$ We found a barrier of $27.31 \mathrm{kcal} / \mathrm{mol}$ for this process (TS_EF), thus higher than the one for the process starting from A. The next step from intermediate F is the creation of the N-Si bond and the calculated energy is the highest one found during this mechanistic study (TS_FG, $33.69 \mathrm{kcal} / \mathrm{mol}$ ). Therefore, it rules out the mechanism starting from imine interacting through $\pi$ system, and reinforces the mechanism of hydrocobaltation followed by sigma-bond metathesis.

In order to obtain more insight on the electronic effect of the imine in the hydrocobaltation and the ligand exchange steps, we studied the variation of substituents on the para position of the two 
phenyl groups by the DFT calculations ( $\mathrm{OMe}, \mathrm{H}$ and $\mathrm{CF}_{3}$ as substituent) and no significant energy difference for the hydrocobaltation step was observed (Figure 8 right and left).

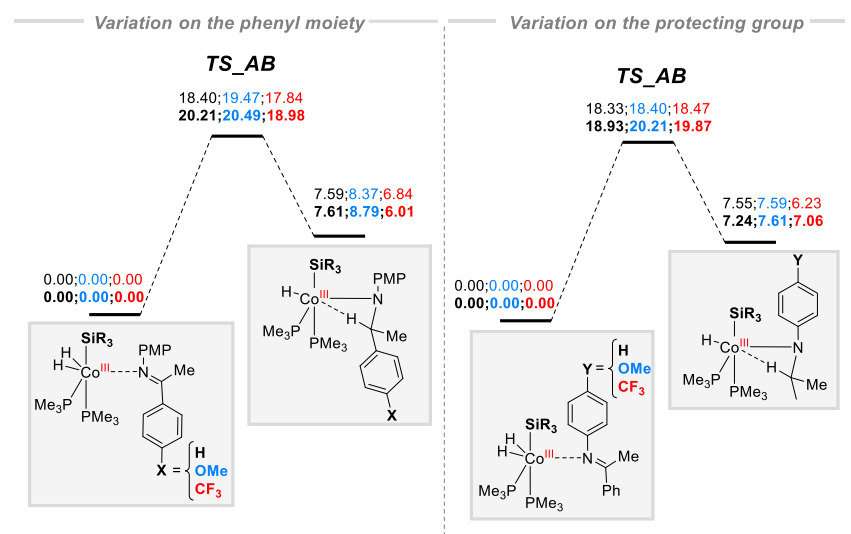

Figure 8. DFT hydrocobaltation step comparison by varying substituents on the imine moiety. Values in normal and bold fonts correspond respectively to the enthalpy and Gibbs free energies (in kcal.mol ${ }^{-1}$ ).

We also ran two competition experiments at different temperatures $\left(110^{\circ} \mathrm{C}\right.$ and $\left.80{ }^{\circ} \mathrm{C}\right)$ with a deficit of silane and we followed the conversion by ${ }^{1} \mathrm{H}$ NMR spectroscopic analysis. While looking at the substitution of the aryl ring at the alpha position of the imine, no difference of reactivity was observed as these transformations led to a 1:1 mixture of both products (see Scheme S2), in accordance with our calculations. However, when looking at the nitrogen protecting group, the product ratio was $80 / 20$ in favour of OMe substitution (see Scheme S3 and S4). The fact that the calculated hydrocobaltation energy was the same however with a difference in product ratio seems to indicate that ligand exchange could be the rate-limiting step of the catalytic cycle. To reinforce this hypothesis, we performed more DFT calculations. Notably, investigating the ligand exchange process with static DFT calculations is a complicated problem. Indeed, ligand exchange can either be an associative or a dissociative process, with implications of solvent molecules (first and second 
layer of solvation). It is thus mainly a dynamic problem and obtaining realistic barriers requires extended ab-initio molecular dynamics simulations which was not studied here.
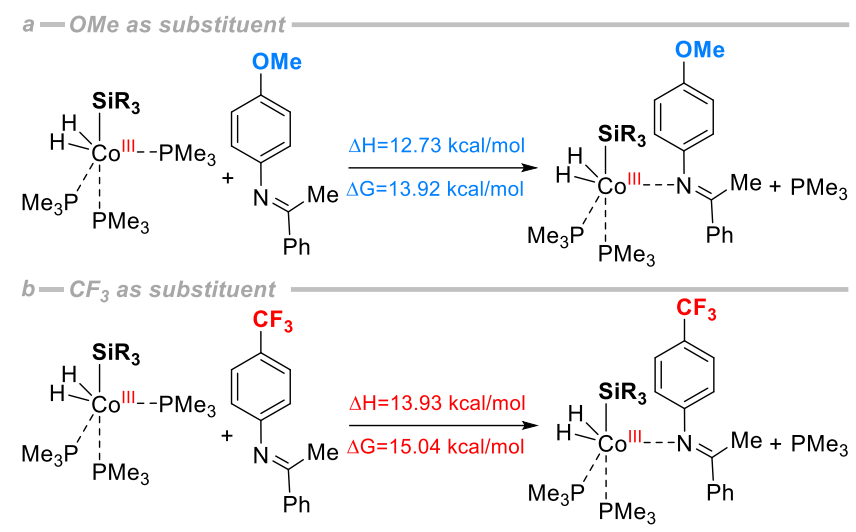

Figure 9. DFT calculations for phosphine exchange by imines.

On the other hand, we were able to calculate thermodynamic parameters for exchanging phosphine by various imines and we found this exchange is endothermic by around $15 \mathrm{kcal} / \mathrm{mol}$ (Figure 9). We note that the exchange by an imine bearing a $\mathrm{CF}_{3}$ group is slightly more difficult than with a OMe group, which could explain the observed differences in reactivity (see Scheme S3). It also implies that barriers for this process are higher than $15 \mathrm{kcal} / \mathrm{mol}$ and thus probably higher than the hydrocobaltation step. 


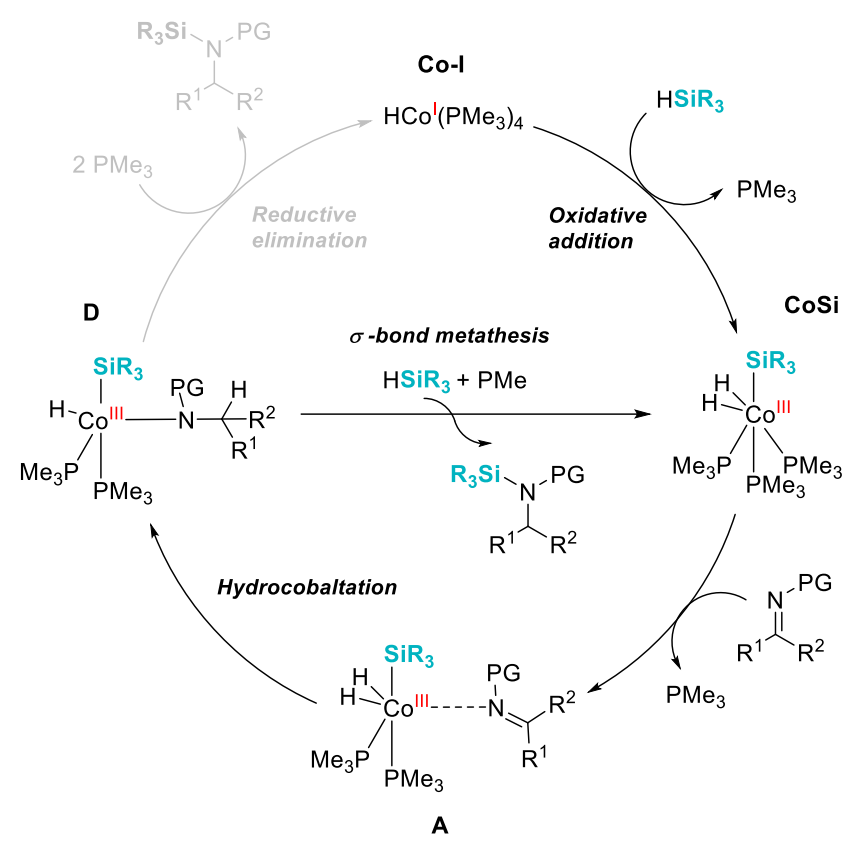

Scheme 4. Proposed mechanism for the hydrosilylation of imines

To summarize the proposed mechanism (Scheme 4), oxidative addition of the silane on the starting cobalt(I) complex Co-I generates the bis-hydrido cobalt(III) complex CoSi, with concomitant loss of one trimethylphosphine ligand. Then ligand exchange occurs between the imine and another phosphine, via a preferential interaction with the nitrogen lone pair. This exchange is probably the rate-limiting step of the catalytic cycle, based on DFT and kinetics studies. It forms intermediate A that undergoes hydrocobaltation on the imine to generate intermediate D. Sigma-bond metathesis ${ }^{37}$ with the silane induces formation of the desired silylated amine and release of the cobalt(III) complex.

In order to test the limits of our reaction conditions we decided to decrease the catalyst loading to $0.1 \mathrm{~mol} \%$ (Scheme $5 \mathrm{a})$. Under these conditions, despite observation of a lower conversion (70\%) after 1 hour, full conversion can be reached after 5 hours. Decreasing catalyst loading by a further factor of ten $(0.01 \mathrm{~mol} \%)$ led to only $5 \%$ of conversion and increasing reaction time to 24 hours 
did not improve reaction outcomes. To prove the efficiency of our system we also ran a gram-scale experiment on imine $\mathbf{1 b}$ that provided full conversion and an isolated yield of $98 \%$ (Scheme $5 \mathrm{~b}$ ).

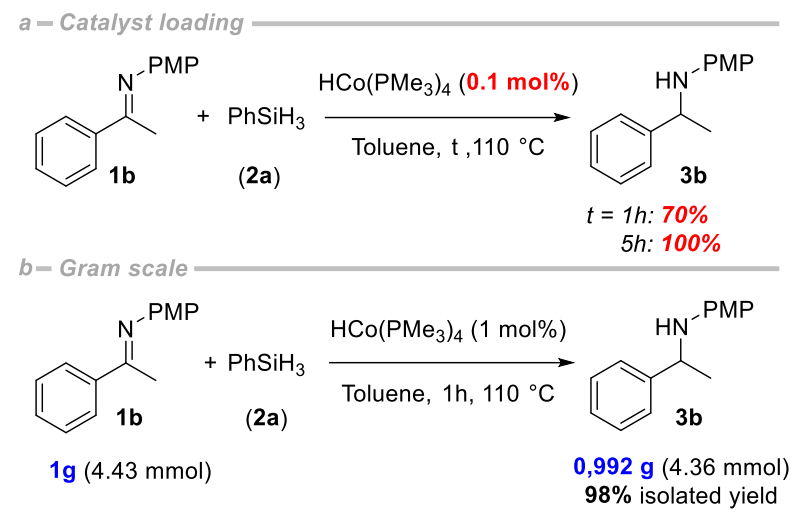

Scheme 5. a) Catalyst loading limits and b) gram-scale reactions

\section{CONCLUSION}

In conclusion we have demonstrated the reactivity of well-defined or in situ generated silyl dihydride cobalt complexes obtained from the simple low-valent cobalt catalyst $\mathrm{HCo}\left(\mathrm{PMe}_{3}\right)_{4}$. Herein, we described the first hydrosilylation of imines catalyzed by a well-defined cobalt complex. This very robust hydrosilylation, with no change of conditions for all the substrates, is applicable on a large scope of imines including aldimines, aryl and aliphatic ketimines bearing various protecting groups but also on quinoline. The reaction conditions tolerate different functionalities and, for most of the imines, the reaction is over in less than one hour with a very low catalyst loading down to $0.1 \mathrm{~mol} \%$. Additionally, deuterium-labeling, kinetics, NMR spectroscopic and computational studies together with the X-ray characterization of a dihydrocobalt(III) intermediate have allowed us to propose a possible mechanism. The isolation, characterization and stability of such dihydrosilylcobalt(III) complexes is a huge step forward 
regarding mechanistic disclosure. Their reactivity and modulation studies are currently under investigation in our laboratory.

\section{ASSOCIATED CONTENT}

The Supporting Information is available free of charge at http:// pubs.acs.org.

Experimental procedures, DFT, kinetic studies and full spectroscopic data for all new compounds (PDF)

Crystallographic data for CoSi-c (CIF)

Crystallographic data for $\mathbf{1 x}(\mathrm{CIF})$

\section{AUTHOR INFORMATION}

\section{Corresponding Author}

*marc.petit@sorbonne-universite.fr

\section{Funding Sources}

This work was supported by CNRS, MRES and Sorbonne Université.

\section{Notes}

The authors declare no competing financial interest.

\section{ACKNOWLEDGMENT}

We warmly thank Geoffrey Gontard for X-ray structure of cobalt(III) complex CoSi-d and Dr. Brendan Fallon for fruitful discussions.

\section{ABBREVIATIONS}


AIM: Atoms in Molecules; BINAP: (2,2'-bis(diphenylphosphino)-1,1'-binaphthyl); Boc: tertbutoxycarbonyle; Bn: benzyl; Bu: butyl; cPr: cyclopropyl; DFT: Density-functional theory; LLHT: ligand to ligand hydrogen transfer; NMR: nuclear magnetic resonance; PG: protecting group; Ph: phenyl; PMHS: Polymethylhydrosiloxane; PMP: p-methoxyphenyl; ppm: parts per million; TMS: trimethylsilyl; Ts: tosyl;

\section{REFERENCES}

${ }^{1}$ Molecular Biology of the Cell, 6th ed., Eds Alberts, B.; Johnson, A.; Lewis, J.; Morgan, D.; Raff, M.; Roberts, K.; Walter, P., New York: Garland Publishing, 2014.

2 a) Lawrence, S. A. Amines: Synthesis, Properties and Applications, Cambridge University Press, Cambridge, 2004; (d) Ricci, A. in Amino Group Chemistry. From Synthesis to the Life Sciences, ed. A. Ricci, Wiley-VCH Verlag GmbH \& Co. KGaA, Weinheim, 2008.

3 a) Lévay, K.; Hegedüs, L. Recent Achievements in the Hydrogenation of Nitriles Catalyzed by Transition Metals Curr. Org. Chem. 2019, 23, 1881-1900; b) Formenti, D.; Ferretti, F.; Scharnagl, F. K.; Beller, M. Reduction of Nitro Compounds Using 3d-Non-Noble Metal Catalysts. Chem. Rev. 2019, 119, 2611-2680; c) Scriven, E. F. V.; Turnbull, K. Azides: their preparation and synthetic uses. Chem. Rev. 1988, 88, 297-368

${ }^{4}$ Wang, D.; Astruc, D. The Golden Age of Transfer Hydrogenation. Chem. Rev. 2015, 115, $6621-6686$.

${ }^{5}$ Li, B.; Sortais, J.-B.; Darcel, C. Amine synthesis via transition metal homogeneous catalysed hydrosilylation. $R S C A d v$. 2016, 6, 57603-57625. 
${ }^{6}$ Chirik, P.; Morris, R. Getting Down to Earth: The Renaissance of Catalysis with Abundant Metals. Acc. Chem. Res. 2015, 48, 2495-2495.

${ }^{7}$ a) Blackwell, J. M.; Sonmor, E. R.; Scoccitti, T.; Piers, W. E. B( $\left.\mathrm{C}_{6} \mathrm{~F}_{5}\right)_{3}$-Catalyzed Hydrosilation of Imines via Silyliminium Intermediates, Org. Lett. 2000, 2, 24, 3921-3923; b) Manas, M. G.; Sharninghausen, L. S.; Balcells, D.; Crabtree, R. H. Experimental and computational studies of borohydride catalyzed hydrosilylation of a variety of $\mathrm{C}=\mathrm{O}$ and $\mathrm{C}=\mathrm{N}$ functionalities including esters amides and heteroarenes New J. Chem. 2014, 38, 1694-1700. c) Yin, Q.; Soltani,Y.; Melen, R. L.; Oestreich, M. BAr ${ }_{3}$-Catalyzed Imine Hydroboration with Pinacolborane Not Requiring the Assistance of an Additional Lewis Base. Organometallics 2017, 36, 2381-2384; d) Elsen, H.; Fischer, C.; Knüpfer, C.; Escalona, A.; Harder, S. Early Main Group Metal Catalysts for Imine Hydrosilylation. Chem. Eur. J. 2019, 25, 16141-16147. e) Kuciński, K.; Hreczycho, G. Hydrosilylation and hydroboration in a sustainable manner: from Earth-abundant catalysts to catalyst-free solutions Green Chem., 2020, 22, 5210-5224. f) Clarke, J. J.; Devaraj, K.; Bestvater, B. P.; Kojima, R.; Eisenberger, P.; DeJesus, J. F.; Crudden, C. M. Hydrosilylation and Mukaiyama aldol-type reaction of quinolines and hydrosilylation of imines catalyzed by a mesoionic carbenestabilized borenium ion. Org. Biomol. Chem., 2021, 19, 6786-6791. g) Pandey, V. K.; Donthireddy, S. N. R.; Rit, A. Catalyst-Free and Solvent-Free Facile Hydroboration of Imines. Chem. - Asian J. 2019, 14, 3255-3258.

${ }^{8}$ Margeson, M. J.; Seeberger, F.; Kelly, J. A.; Leitl, J.; Coburger, P.; Szlosek, R.; Müller, C.; Wolf, R. Expedient Hydrofunctionalisation of Carbonyls and Imines Initiated by Phosphacyclohexadienyl Anions. ChemCatChem 2021, 13, 3761-3764. 
${ }^{9}$ a) Park, B-M.; Mun, S.; Yun, J. Zinc-Catalyzed Enantioselective Hydrosilylation of Imines. Adv. Synth. Catal. 2006, 348, 1029-1032. b) Park, B-M.; Feng, X.; Yun, J.-S. Enantioselective Hydrosilylation of Imines Catalyzed by Diamine-Zinc Complexes. Bull. Korean Chem. Soc. 2011, 32, 2960-2964. c) Lipshutz, B. H.; Shimizu, H. Copper(I)-Catalyzed Asymmetric Hydrosilylations of Imines at Ambient Temperatures. Angew. Chem. Int. Ed. 2004, 43, $2228-2230$.

10 For selected examples and reviews with iron see: a) Shaikh, N. S. Sustainable Amine Synthesis: Iron Catalyzed Reactions of Hydrosilanes with Imines, Amides, Nitroarenes and Nitriles. ChemistrySelect 2019, 4, 6753-6777. b) Saini, A.; Smith, C. R.; Wekesa, F. S.; Helms, A. K.; Findlater, M. Conversion of aldimines to secondary amines using iron-catalysed hydrosilylation. Org. Biomol. Chem. 2018, 16, 9368-9372. c) Zhou, S.; Junge, K.; Addis, D.; Das, S.; Beller, M. A Convenient and General Iron-Catalyzed Reduction of Amides to Amines Angew. Chem. Int. Ed. 2009, 48, 9507-9510. d) Wei, D.; Darcel, C. Iron Catalysis in Reduction and Hydrometalation Reactions. Chem. Rev. 2019, 119, 2550-2610. f) Bhunia, M.; Hota, P. K.; Vijaykumar, G.; Adhikari, D.; Mandal, S. K. A Highly Efficient Base-Metal Catalyst: Chemoselective Reduction of Imines to Amines Using An Abnormal-NHC-Fe(0) Complex. Organometallics 2016, 35, 2930-2937. g) Misal Castro, L. C.; Sortais, J.-B.; Darcel, C. NHCcarbene cyclopentadienyl iron based catalyst for a general and efficient hydrosilylation of imines. Chem. Commun. 2012, 48, 151-153.

11 Bheeter, L. P.; Henrion, M.; Chetcuti, M. J.; Darcel, C.; Ritleng, V.; Sortais, J.-B. Cyclopentadienyl N-heterocyclic carbene-nickel complexes as efficient pre-catalysts for the hydrosilylation of imines. Catal. Sci. Technol. 2013, 3, 3111-3116. 
12 Cobalt Catalysis in Organic Synthesis: Methods and Reactions; Hapke, M.; Hilt, G.; Eds, Wiley-VCH Verlag GmbH \& Co. KGaA 2020.

13 Ai, W.; Zhong, R.; Liu, X.; Liu, Q. Hydride Transfer Reactions Catalyzed by Cobalt Complexes. Chem. Rev. 2019, 119, 2876-2953.

${ }^{14}$ Kobayashi, K.; Okamoto, T.; Oida, T.; Tanimoto, S. Cobalt-mediated Reduction of C=N Bond. Synthesis of Methyl $N$-p-Toluenesulfonyl-1-phenylglycinate Catalyzed by Bis (dioximato)cobalt-Quinine Complexes. Chem. Lett. 1986, 15, 2031-2034.

15 Amèzquita-Valencia, M.; Cabrera, A. The First Example of' Asymmetric Hydrogenation of Imines with $\mathrm{Co}_{2}(\mathrm{CO})_{8} /(\mathrm{R})-\mathrm{BINAP}$ as Catalytic Precursor. J. Mol. Catal. A: Chem. 2013, 366, $17-21$.

16 Zhang, G.; Scott, B. L.; Hanson, S. K. Mild and Homogeneous Cobalt-Catalyzed Hydrogenation of $\mathrm{C}=\mathrm{C}, \mathrm{C}=\mathrm{O}$, and $\mathrm{C}=\mathrm{N}$ Bonds. Angew. Chem. Int. Ed. 2012, 51, 12102-12106.

${ }^{17}$ Gärtner, D.; Welther, A.; Rezaei Rad, B.; Wolf, R.; Von Wangelin, A. J. Heteroatom-Free Arene-Cobalt and Arene-Iron Catalysts for Hydrogenations. Angew. Chem. Int. Ed. 2014, 53, $3722-3726$.

${ }^{18}$ For a single example (with no yield) that is part of a high-throughput screening see: Ireland, T.; Fontanet, F.; Tchao, G.-G. Identification of new catalysts for the asymmetric reduction of imines into chiral amines with polymethylhydrosiloxane using high-throughput screening. Tetrahedron Lett. 2004, 45, 4383-4387. 
19 a) Ventre, S.; Simon, C.; Rekhroukh, F.; Malacria, M.; Amatore, M.; Aubert, C.; Petit, M. Catalytic Version of Enediyne Cobalt-Mediated Cycloaddition and Selective Access to Unusual Bicyclic Trienes. Chem. Eur. J. 2013, 19, 5830-5835. b) Ventre, S.; Derat, E.; Amatore, M.; Aubert, C.; Petit, M. Hydrido-Cobalt Catalyst as a Selective Tool for the Dimerisation of Arylacetylenes: Scope and Theoretical Studies. Adv. Synth. Catal. 2013, 355, 2584-2590. c) Fallon, B. J.; Derat, E.; Amatore, M.; Aubert, C.; Chemla, F.; Ferreira, F.; Perez-Luna, A.; Petit, M. C-H Activation/Functionalization Catalyzed by Simple, Well-Defined Low-Valent Cobalt Complexes. J. Am. Chem. Soc. 2015, 137, 2448-2451. d) Fallon, B. J.; Garsi, J.-B.; Derat, E.; Amatore, M.; Aubert, C.; Petit, M. Synthesis of 1,2-Dihydropyridines Catalyzed by Well-Defined Low-valent Cobalt Complexes: C-H Activation Made Simple. ACS Catal. 2015, 5, 7493-7497. e) Fallon, B. J.; Derat, E.; Amatore, M.; Aubert, C.; Chemla, F.; Ferreira, F.; Perez-Luna, A.; Petit, M. C2-Alkylation and Alkenylation of Indoles Catalyzed by a Low-Valent Cobalt Complex in the Absence of Reductant. Org. Lett. 2016, 18, 2292-2295. f) Rivera-Hernandez, A.; Fallon, B. J.; Ventre, S.; Simon, C.; Tremblay, M. H.; Gontard, G.; Derat, E.; Amatore, M.; Aubert, C.; Petit, M. Regio- and Stereoselective Hydrosilylation of Unsymmetrical Alkynes Catalyzed by a WellDefined, Low-Valent Cobalt Catalyst. Org. Lett. 2016, 18, 4242-4245. g). Fallon, B. J.; Corcé, V.; Amatore, M.; Aubert, C.; Chemla, F.; Ferreira, F.; Perez-Luna, A.; Petit, M. A Well-defined Low-Valent Cobalt Catalyst $\mathrm{RCo}\left(\mathrm{PMe}_{3}\right)_{4}$ with Dimethylzinc: A Simple Catalytic Approach for the Reductive Dimerization of Benzyl Halides. New J. Chem. 2016, 40, 9912-9916. h) Ferrand, L.; Lyu, Y.; Rivera-Hernández, A.; Fallon, B. J.; Amatore, M.; Aubert, C.; Petit, M. Hydroboration and Diboration of Internal Alkynes Catalyzed by a Well-Defined Low-Valent Cobalt Catalyst, Synthesis 2017, 49, 3895-3904. 
${ }^{20}$ For selected examples from other groups: a) Li, J.; Li, X.; Wang, L.; Hu, Q.; Sun, H. C-Cl bond activation and catalytic hydrodechlorination of hexachlorobenzene by cobalt and nickel complexes with sodium formate as a reducing agent. Dalton Trans. 2014, 43, 6660-6666. b) Beck, R.; Camadanli, S.; Flörke, U.; Klein, H.-F. Reaction cascade: Ortho-C-H activation and C-C coupling of benzophenone leading to tetranuclear organoiron and mononuclear organocobalt complexes. J. Orgamet. Chem. 2015, 778, 47-55. c) Rajpurohit, J.; Kumar, P.; Shukla, P.; Shanmugam, M.; Shanmugam, M. Mechanistic Investigation of Well-Defined Cobalt Catalyzed Formal E-Selective Hydrophosphination of Alkynes. Organometallics 2018, 37, 2297-2304. d) Li, Y.; Krause, J. A.; Guan, H. Silane Activation with Cobalt on the POCOP Pincer Ligand Platform. Organometallics 2020, 39, 3721-3730.

${ }^{21}$ Suslick, B. A.; Tilley, T. D. Mechanistic Interrogation of Alkyne Hydroarylations Catalyzed by Highly Reduced, Single-Component Cobalt Complexes. J. Am. Chem. Soc. 2020, 142, 1120311218.

${ }^{22} \mathrm{We}$ investigated the possibility of an auto-catalyzed hydrosilylation by putting $10 \mathrm{~mol} \%$ of deprotonated amine in absence of cobalt and no conversion was observed.

23 Pang, M; Chen, J.-Y.; Zhang, S.; Liao, R.-Z.; Tung, C.-H.; Wang, W. Controlled partial transfer hydrogenation of quinolines by cobalt-amido cooperative catalysis Nat. Commun. 2020, $11,1249-1258$.

24 a) Hermeke, J.; Klare, H. F. T.; Oestreich, M. Direct Catalytic Access to N-Silylated Enamines from Enolizable Imines and Hydrosilanes by Base-Free Dehydrogenative Si-N Coupling. Chem. Eur. J. 2014, 20, 9250-9254. b) Pèrez-Miqueo, J.; San Nacianceno, V.; Urquiola, F. B.; Freixa, Z. 
Revisiting the iridacycle-catalyzed hydrosilylation of enolizable imines. Catal. Sci. Technol. 2018, $8,6316-6329$.

${ }^{25}$ A control experiment showed that a rapid scrambling between $\mathrm{Ph}_{2} \mathrm{SiH}_{2}$ and $\mathrm{Ph}_{2} \mathrm{SiD}_{2}$ is catalyzed by the $\mathrm{HCo}\left(\mathrm{PMe}_{3}\right)_{4}$ complex even at rt (See Supporting Information).

${ }^{26}$ This cobalt(III) complex with $\mathrm{Ph}_{2} \mathrm{SiH}_{2}$ was recently proposed as a key intermediate but not isolated see : Yang, Qi W.; Fan, Q.; Du, X.; Xie, S.; Huang, W.; Li, X.; Sun, H.; Fuhr, O.; Fenske, D. [P,C]-Chelate Cobalt(III) Hydride Catalyzed Hydrosilylation of Alkenes. Organometallics 2021, 40, 2836-2843.

${ }^{27}$ Mautz, J.; Heinze, K.; Wadepohl, H.; Huttner, G. Reductive Activation of tripod Metal Compounds: Identification of Intermediates and Preparative Application. Eur. J. Inorg. Chem. 2008, 1413-1422.

${ }^{28}$ Handford, R. C.; Smith, P. W.; Tilley, D. T. Activations of all Bonds to Silicon (Si-H, Si-C) in a Silane with Extrusion of [CoSiCo] Silicide Cores. J. Am. Chem. Soc. 2019, 141, 8769-8772

${ }^{29}$ Nolin, K. A.; Krumper, J. R.; PLuth, M. D.; Bergman, R. G.; Toste, F. D. Analysis of an Unprecedented Mechanism for the Catalytic Hydrosilylation of Carbonyl Compounds. J. Am. Chem. Soc., 2007, 129, 14684-14696.

${ }^{30}$ Lipke, M. C.; Liberman-Martin, A. L.; Tilley. T. D. Electrophilic Activation of SiliconHydrogen Bonds in Catalytic Hydrosilations. Angew. Chem. Int. Ed. 2017, 56, 2260 - 2294. 
31 a) Friestad, G. K. Addition of carbon-centered radicals to imines and related compounds. Tetrahedron 2001, 5 7, 5461-5496; b) Miyabe, H.; Yoshioka, E.; Kohtani, S. Progress in Intermolecular Carbon Radical Addition to Imine Derivatives Current Organic Chemistry, 2010, 14, 1254-1264; c) Garrido-Castro, A.F.; Maestro, M.C.; Alemán, J. a-Functionalization of Imines via Visible Light Photoredox Catalysis. Catalysts 2020, 10, 562-584.

${ }^{32}$ Kyne, S. H.; Lefèvre, G.; Ollivier, C.; Petit, M.; Ramis Cladera, V-A.; Fensterbank, L. Iron and cobalt catalysis: new perspectives in synthetic radical chemistry. Chem. Soc. Rev., 2020, 49, $8501-8542$.

${ }^{33}$ Mendelsohn, L. N.; MacNeil, C. S.; Tian, L.; Park, Y.; Scholes, G. D.; Chirik, P. J. VisibleLight-Enhanced Cobalt-Catalyzed Hydrogenation: Switchable Catalysis Enabled by Divergence between Thermal and Photochemical Pathways ACS Catal. 2021, 11, 1351-1360

34 Coeffard, V.; Thobie-Gautier, C.; Beaudet, I.; Le Grognec, E.; Quintard, J-P. Mild Electrochemical Deprotection of N-Phenylsulfonyl N-Substituted Amines Derived from (R)Phenylglycinol. Eur. J. Org. Chem. 2008, 383-391.

${ }^{35}$ Wertz, D. H. Relationship between the gas-phase entropies of molecules and their entropies of solvation in water and 1-octanol. J. Am. Chem. Soc. 1980, 102, 5316-5322.

${ }^{36}$ Cooper, J.; Ziegler, T. A Density Functional Study of $\mathrm{S}_{\mathrm{N}} 2$ Substitution at Square-Planar Platinum(II) Complexes. Inorg. Chem. 2002, 41, 6614-6622.

${ }^{37}$ We cannot totally exclude a mechanism through a reductive elimination. 


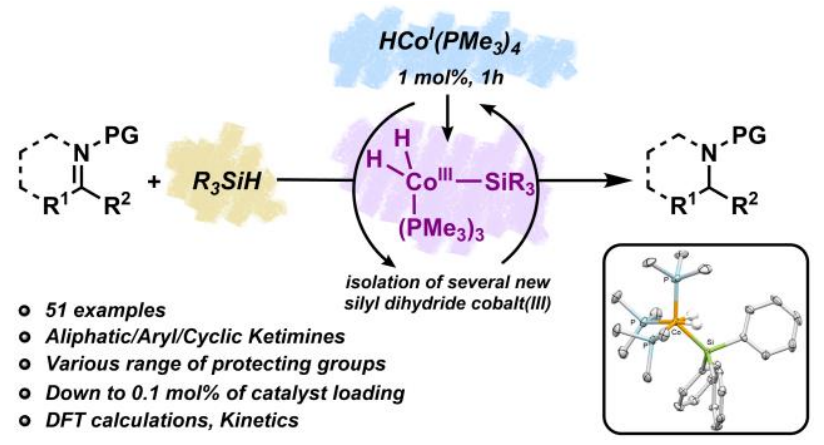

